\title{
SITING OF A CENTRAL HEALTHCARE WASTE INCINERATOR USING GIS-BASED MULTI-CRITERIA DECISION ANALYSIS
}

\section{Husna Ali Hariz}

Masters Thesis Ind ustrial Engineering

Thesis Supervisor

Assist. Prof. Cem Çağrı Dönmez

Thesis CO-Supervisor Assoc. Prof. Dr. Bahar Sennaroğlu ISTANBUL, 2017 


\section{SITING OF A CENTRAL HEALTHCARE WASTE INCINERATOR USING GIS-BASED MULTI-CRITERIA DECISION ANALYSIS}

\section{Husna Ali Hariz} $(524412921)$

Masters Thesis Ind ustrial Engineering

Thesis Supervisor

Assist. Prof. Cem Çağrı Dönmez

Thesis CO-Supervisor Assoc. Prof. Dr. Bahar Sennaroğlu ISTANBUL, 2017 


\title{
SITING OF A CENTRAL HEALTHCARE WASTE INCINERATOR USING GIS-BASED MULTI-CRITERIA DECISION ANALYSIS
}

\author{
Husna Ali Hariz
}

YÜKSEK LISANS TEZI

Endüstri Muhend isliği

D ANIŞMAN

Yrd. Doç. Dr. Cem Çağrı Dönmez

II-DANIŞMAN

Doç. Dr. Bahar Sennaroğlu

ISTANBUL, 2017 


\section{MARMARA UNIVERSITY \\ INSTITUTE FOR GRADUATE STUDIES \\ IN PURE AND APPLIED SCIENCES}

Husna Ali HARIZ, a Master of Science student of Marmara University Institute for Graduate Studies in Pure and Applied Sciences, defended her thesis entitled "SITING OF A CENTRAL HEALTHCARE WASTE INCINERATOR USING GIS-BASED MULTI-CRITERIA DECISION ANALYSIS", on January 26, 2017 and has been found to be satisfactory by the jury members.

\section{Jury Members}

Asst. Prof. Dr. Cem Çağn DÖNMEZ

Marmara University

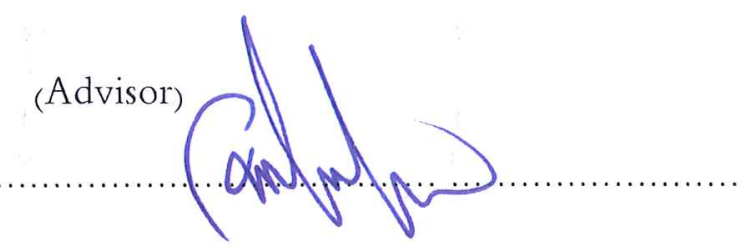

Jury Member)

Assoc. Prof. Dr. Serol BULKAN

resed leathn.

Marmara University

Assoc. Prof. Dr. Hakan TOZAN

Jury Member)

Medipol University

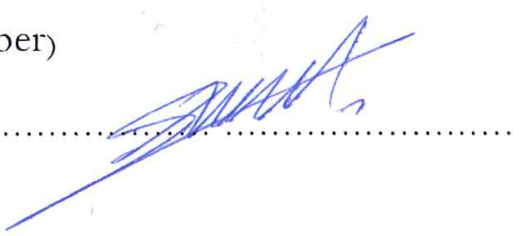

\section{APPROVAL}

Marmara University Institute for Graduate Studies in Pure and Applied Sciences Executive Committee approves that Husna Ali HARIZ be granted the degree of Master of Science in Department of Industrial Engineering, Industrial Engineering Program on 30.01 .2017 (Resolution no: $2017103-02$ ).

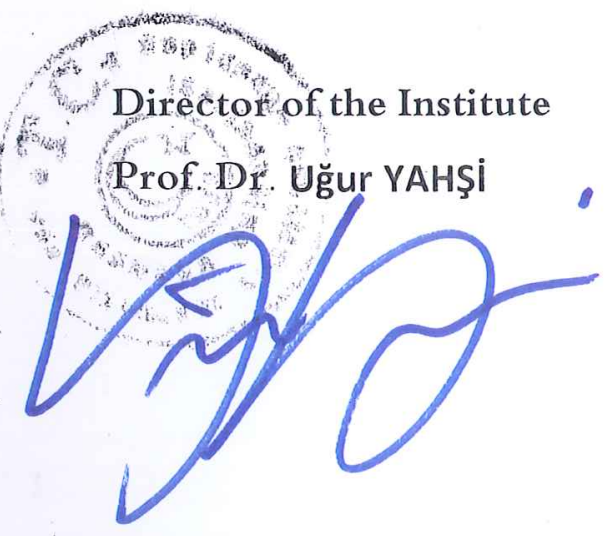




\section{ACKNOWLEDGEMENT}

I would like to thank my supervisor, Asst. Prof. Dr. CEM ÇAĞRI DÖNMEZ, for his invaluable insight and for providing me with his generous assistance and support during the course of this thesis. I owe particular gratitude to Assoc. Prof. Dr. BAHAR SENNAROĞLU for her invaluable contribution, criticism, comments and motivation. Last but not least, I certainly present my gratitude to my beloved family for their endless support and patience that helped me overcome this tough period of study. Finally, I hope this study will provide some guidance to those who are interested in the topic. 


\section{TABLE OF CONTENTS}

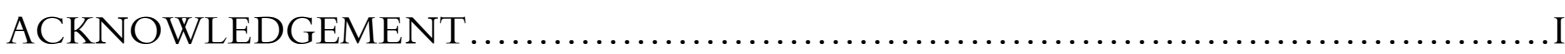

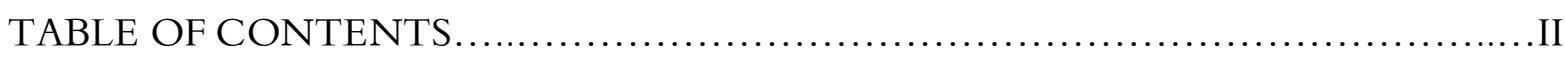

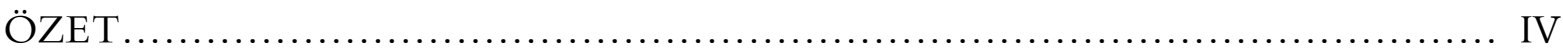

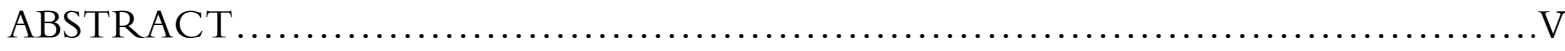

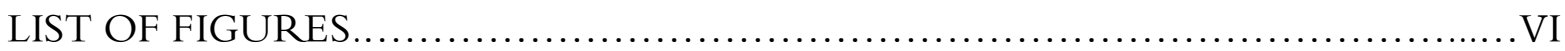

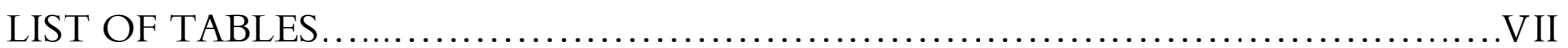

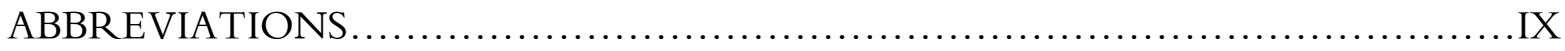

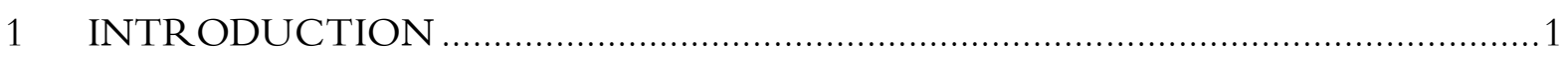

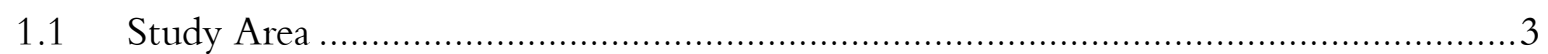

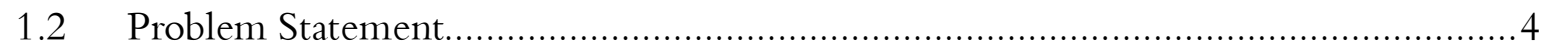

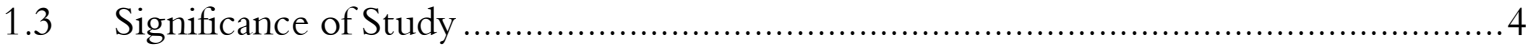

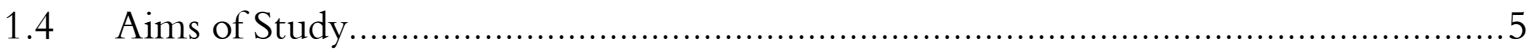

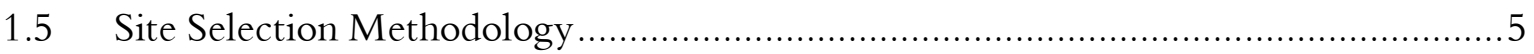

1.5.1 Geographical Information Systems (GIS) ….......................................... 5

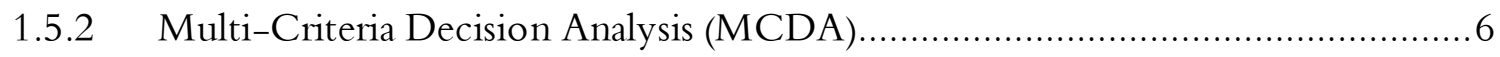

1.5.3 Spatial Multi-Criteria Decision Analysis (SMCDA) ......................................... 6

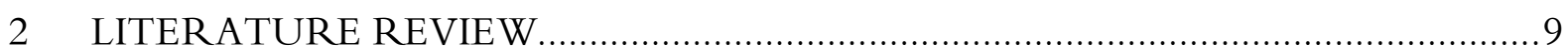

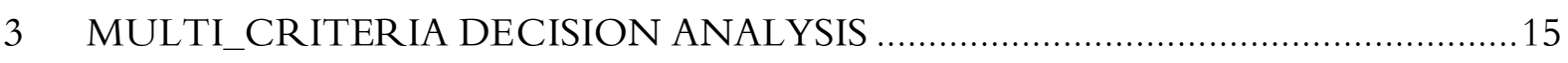

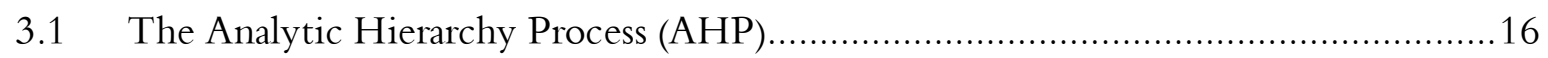

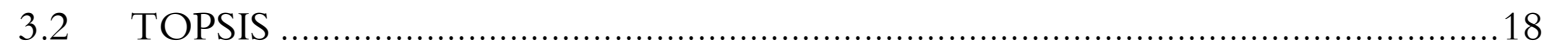

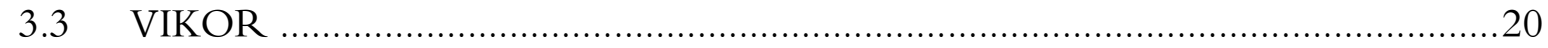

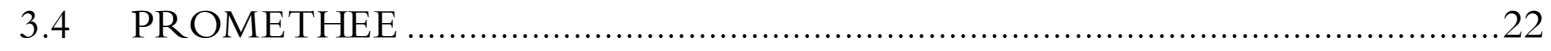

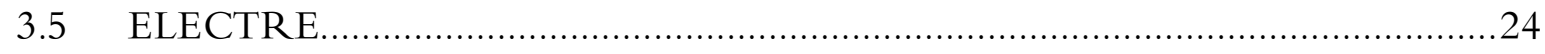

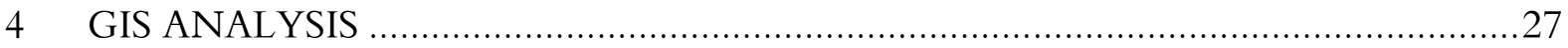




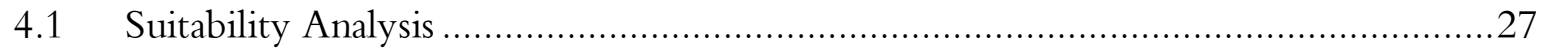

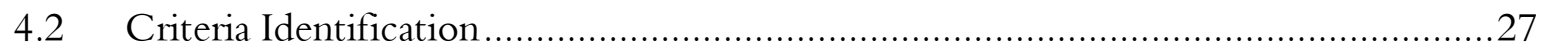

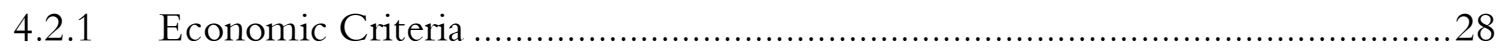

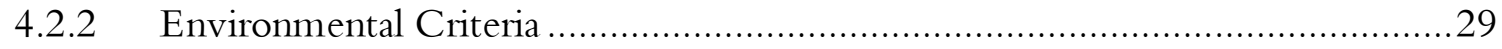

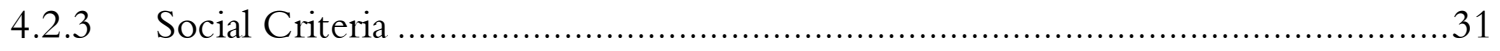

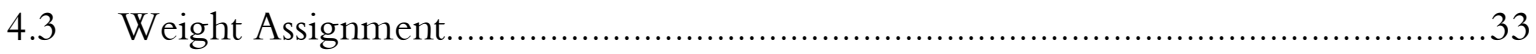

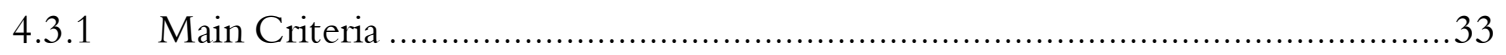

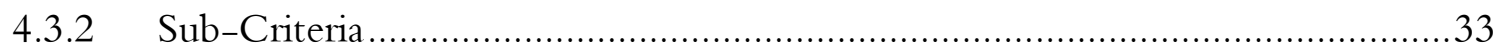

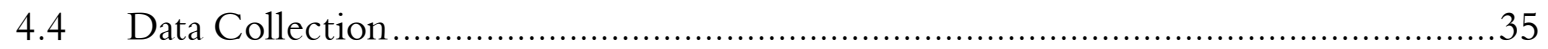

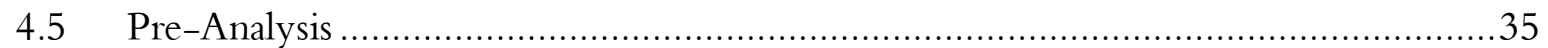

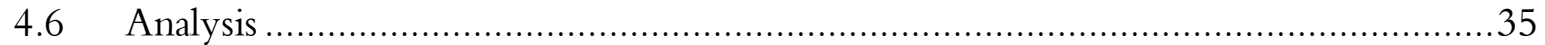

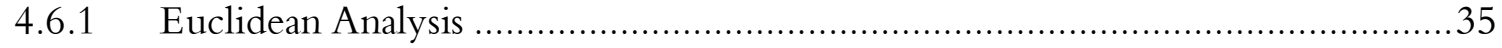

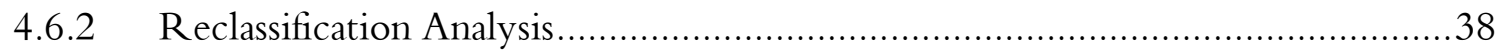

4.6.3 Weighted Overlay Analysis.................................................................. 41

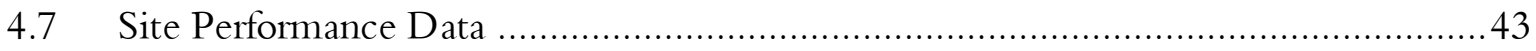

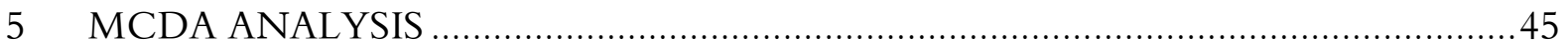

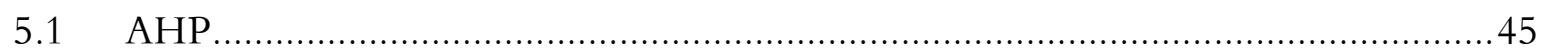

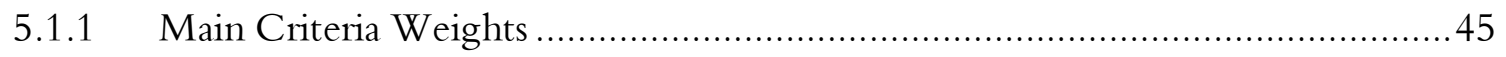

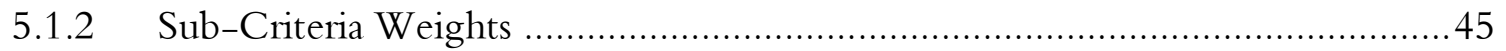

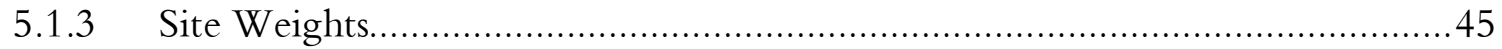

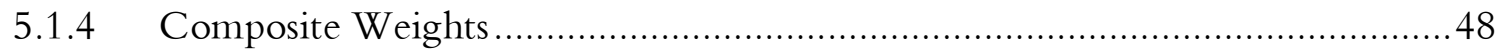

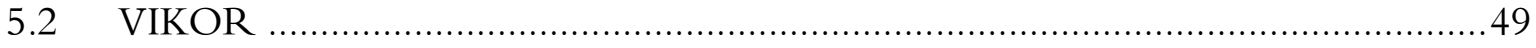

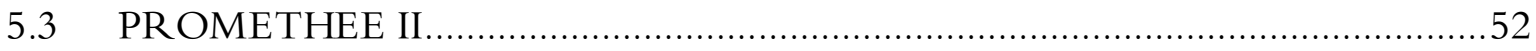

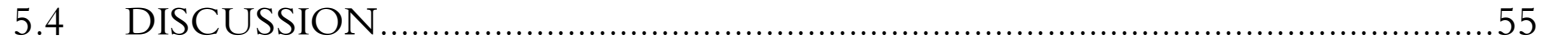

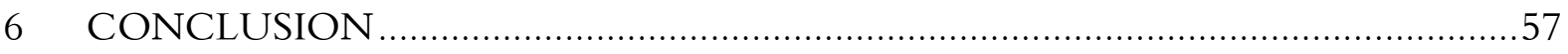

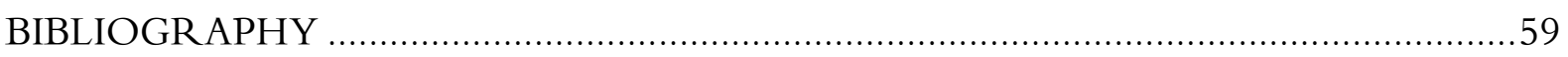

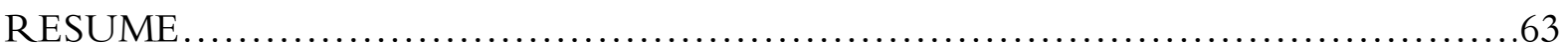




\section{ÖZET}

\section{MERKEZİ SAĞLIK ATIKLARI YAKMA TESISINININ CBS TABANLI ÇOKLU KRİTER KARAR ANALIZII İLE YERLEŞTİRILLMESİ}

$\mathrm{Bu}$ çalışma, Kenya'daki sağlıssı atık yönetimi sorununa bakmaktadır. Çoğu sağlık kuruluşunda, düzenleyici organların uyumluluk sağlamak için sistemli bir gözetim planından yoksun olması nedeniyle, sağlı bakım atıklarının taşınması ve bertaraf edilmesi için mevcut mevzuatın uygulanmasından yoksundur. Açık havada yakma gibi sağlı atıklarının uygunsuz bir şekilde arıtılması veya yok edilmesi, çevreye önemli bir kirlilik kayna ğı oluşturabilir ve dioksinler, furanlar ve cıva gibi maddelerin salınması ile sa ğlık açısından tehlikeli olabilmektedir. Sağlık kuruluşlarının atıklarını düzgün bir şekilde idare etme konus unda bir taahhüdü olmadı ğı kabul edildiğinde, fon eksikliğinin bu durumun başlıca sebeplerinden biri olduğu görmezden gelinemez. Mevcut engeller ne olursa olsun, sa ğlı atıklarının güvenli yönetimi vazgeçilmezdir. Bu tez, merkezi bir modern atık yakma tesisinin kurulmasıla yukanda özetlenen problemlerin üstesinden gelmeyi kolaylaştıracağını önermektedir. Bu tez Cenevre Enformasyon Sistemleri (CBS) tekniklerini, Kenya Kıyısı ilinin Kilifi İlçesindeki potansiyel alanları analiz etmek ve değerlendirmek için Çok Kriterli Karar Analizi yöntemleriyle birleştirmektedir. Çalışma için, mekansal analizlerden sekiz potansiyel alan belirlenmiş ve bu alanlar AHP, VIKOR ve PROMETHEE kullanılarak analiz edilmiştir. Elde edilen sonuçlar üç metotta da tutarlı sonuçlar vermiş ve en iyi alanın büyük Malindi kasabası civarında olduğu tespit edilmiştir.

ANAHTAR SÖZCÜKLER: Yakma Fırınlarının Konumlandırılması, Sağlık Atıkları, CBS, MCDA, AHP, VIKOR, PROMETHEE 


\section{ABSTRACT}

\section{SITING OF A CENTRAL HEALTHCARE WASTE INCINERATOR USING GIS-BASED MULTI-CRITERIA DECISION ANALYSIS}

This study looks into the problem of poor healthcare waste management in Kenya. Most healthcare facilities lack enforcement of existing legislation for handling, and disposal of health care waste, an issue exacerbated by the fact that regulating bodies lack a systemized oversight plan of ensuring compliance. Improper treatment or disposal of healthcare waste such as openair burning can constitute a significant source of pollution to the environment and a health hazard through the release of substances such as dioxins, furans and mercury. In as much as it is recognized that healthcare facilities lack a commitment to properly handle their waste, one cannot ignore the fact that lack of funds is a major cause for this situation. Regardless of the obstacles present, safe management of healthcare waste is indispensable. This thesis suggests setting up a centralized modern waste incinerator will facilitate in overcoming the problems outlined above. This thesis integrates Geographical Information Systems (GIS) techniques with Multi-Criteria Decision Analysis methods to analyse and evaluate potential sites in the Kilifi County of the Kenyan Coast province. The study identified eight potential sites from a spatial analysis. These sites were then analysed using AHP, VIKOR and PROMETHEE. The results obtained were consistent across all three methods and the best site was found to be near the major town of Malindi.

KEYWORDS: Incinerator Siting, Healthcare Waste, GIS, MCDA, AHP, VIKOR, PROMETHEE 


\section{LIST OF FIGURES}

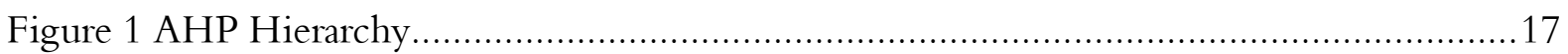

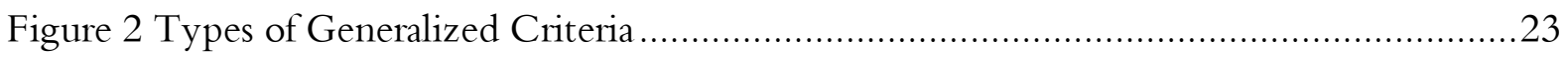

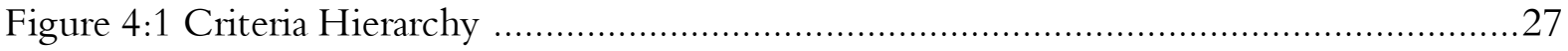

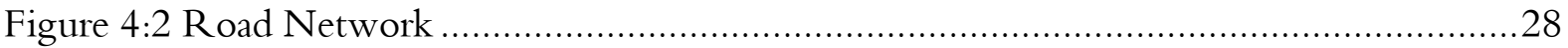

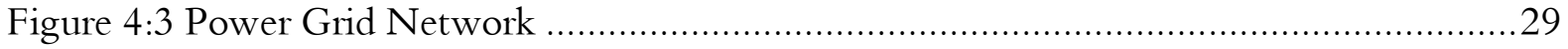

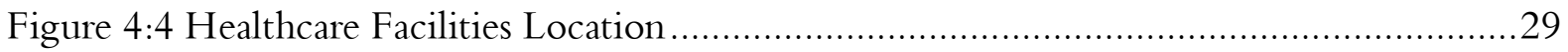

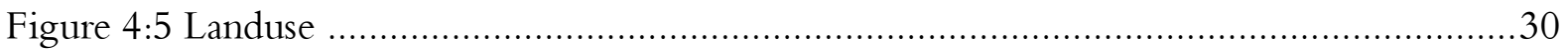

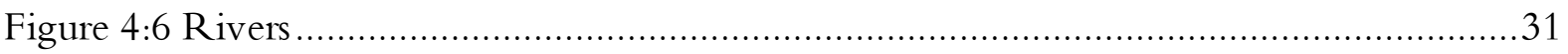

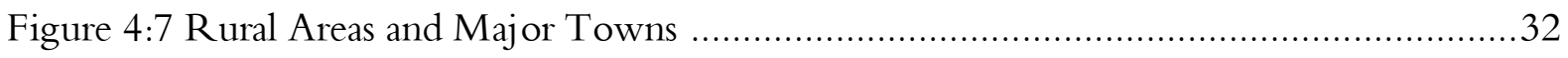

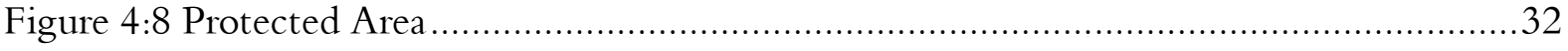

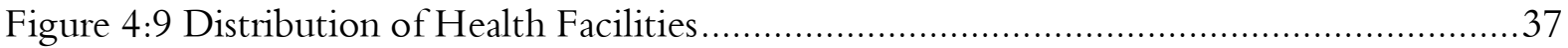

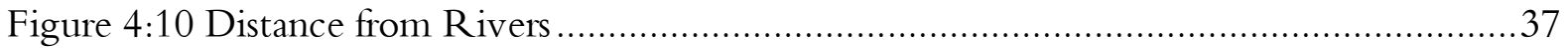

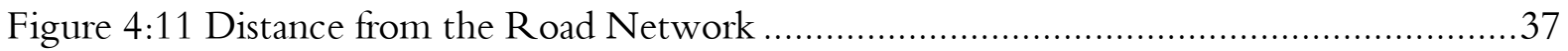

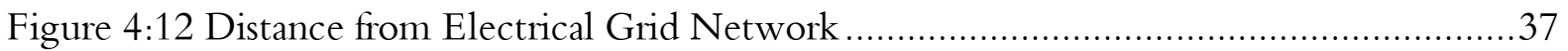

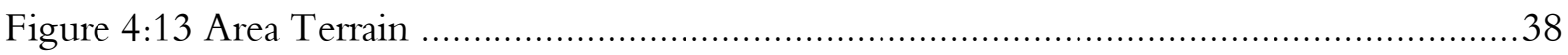

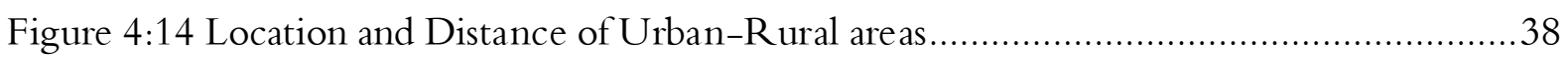

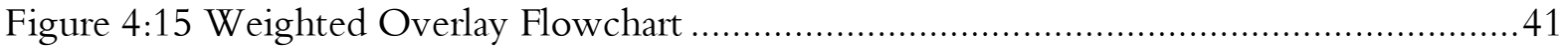

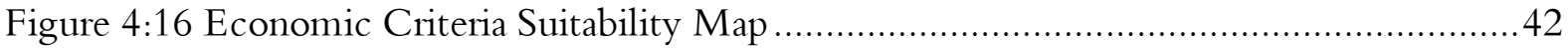

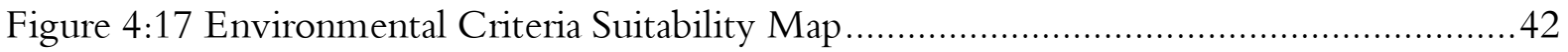

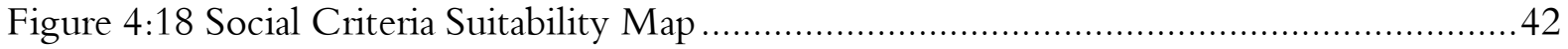

Figure 4:19 Combined Criteria Suitability Map ................................................................ 42

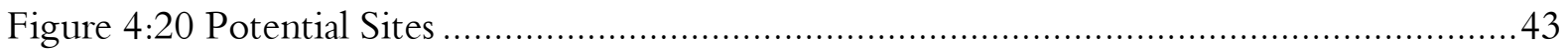

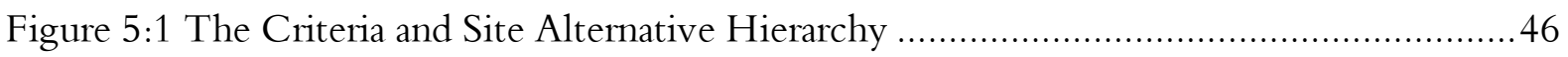




\section{LIST OF TABLES}

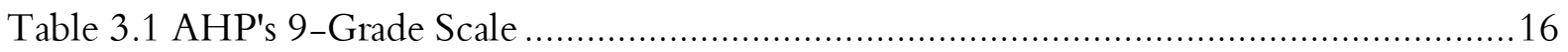

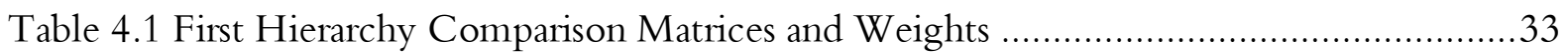

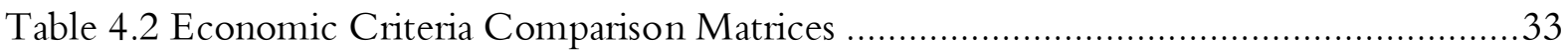

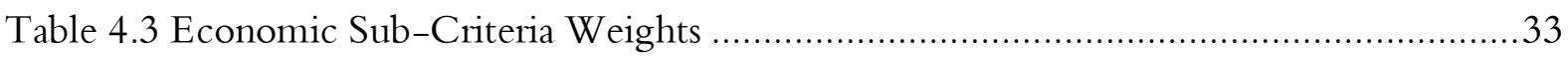

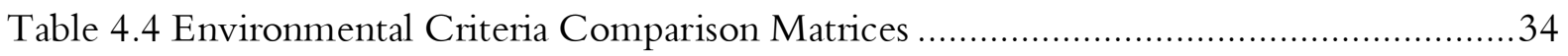

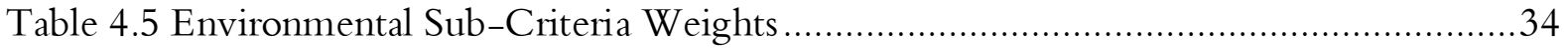

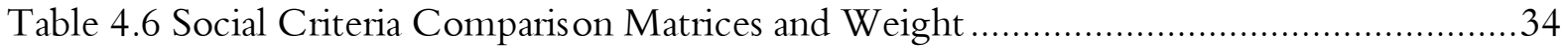

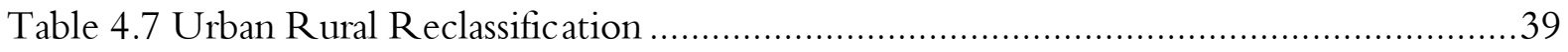

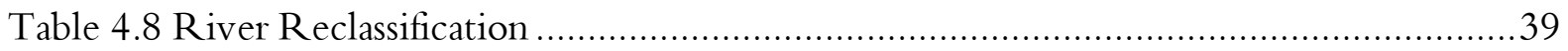

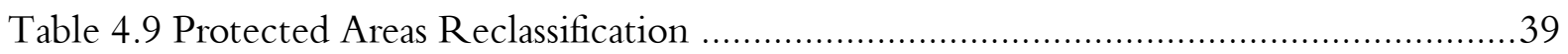

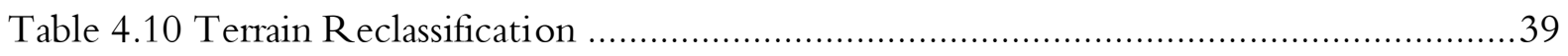

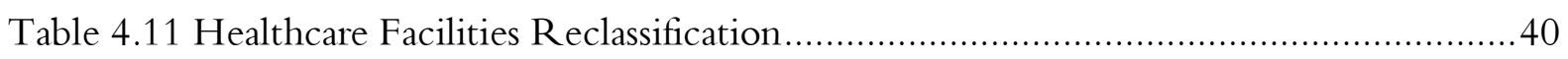

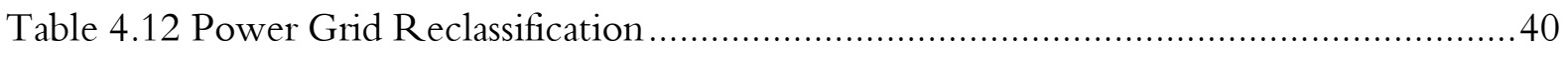

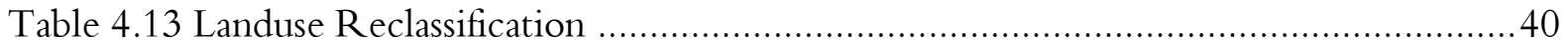

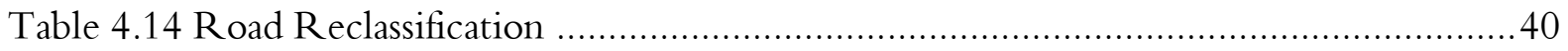

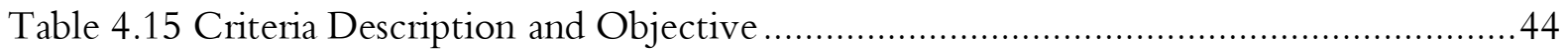

Table 4.16 Site Performance Data Per Criteria ....................................................................... 44

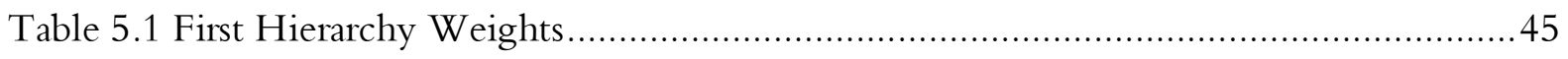

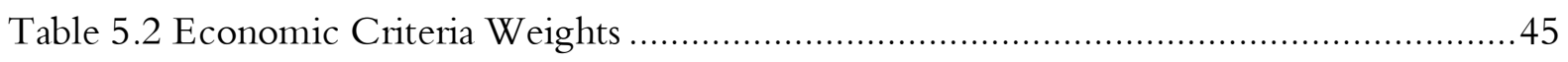

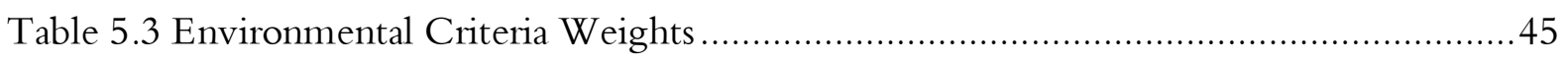

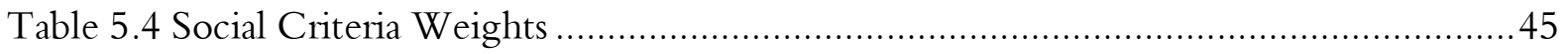

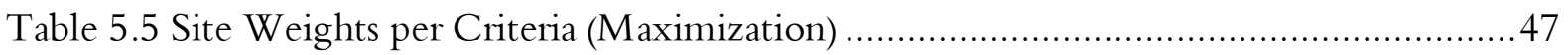

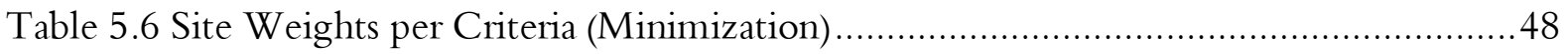

Table 5.7 AHP Composite Weights and Ranking for Sites ................................................ 49

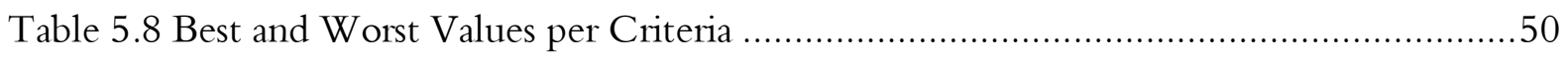

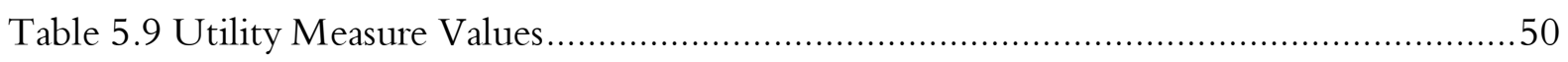

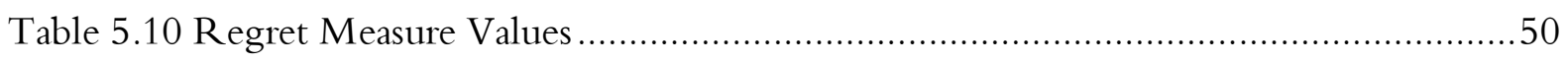

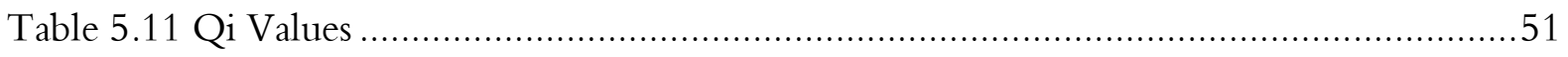

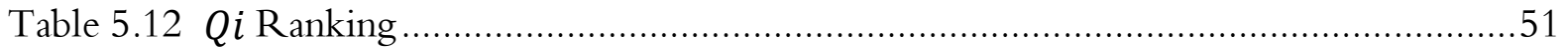

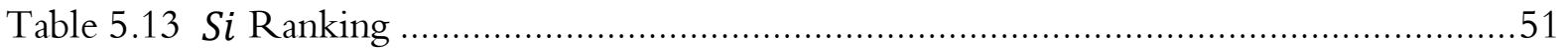

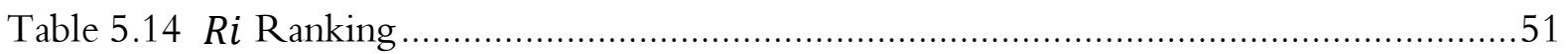


Table 5.15 AHP Composite Weights .52

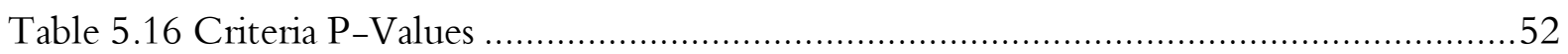

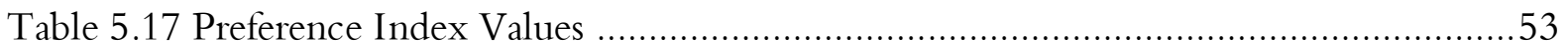

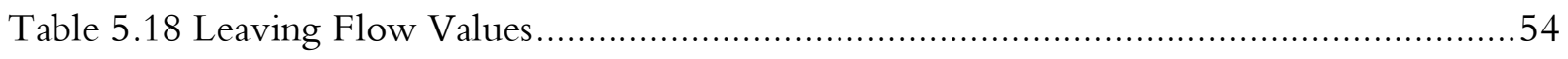

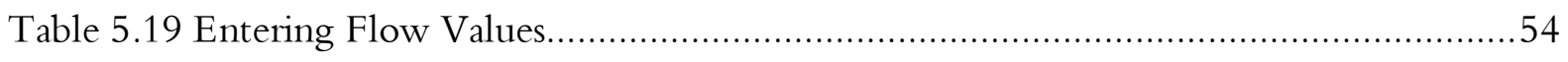

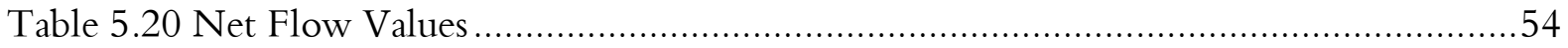

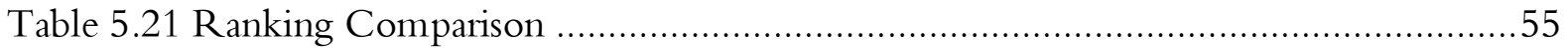




\section{ABBREVIATIONS}

\begin{tabular}{|c|c|}
\hline AHP & Analytic Hierarchy Process \\
\hline ANP & Analytic Network Process \\
\hline CGT & Cooperative Game Theory \\
\hline CI & Consistency Index \\
\hline ELECTRE & Elimination and Choice Expressing Reality \\
\hline FAO & Food and Agricultural Organization \\
\hline GIS & Geographical Information Systems \\
\hline IMILP & Inexact Mixed Integer Linear Programming \\
\hline IMGP & Interactive Multiple Goal Programming \\
\hline KPLC & Kenya Power and Lighting Company \\
\hline MCDA & Multi-Criteria Decision Analysis \\
\hline MSW & Municipal Solid Waste \\
\hline NEMA & National Environmental Management Agency \\
\hline PHC & Primary Healthcare Centre \\
\hline PROMETHEE & Preference Ranking Organization Method for Enriching Evaluations \\
\hline RI & Random Consistency Index \\
\hline SAW & Simple Additive Weight \\
\hline SMCDA & Spatial Multi-Criteria Decision Analysis \\
\hline SRTM & Shuttle Radar Topography Mission \\
\hline STEM & Step Method \\
\hline SWA & Simple Weighted Addition \\
\hline TOPSIS & Technique for Order Preference by Similarity to Ideal Solution \\
\hline USAID & United States Agency for International Development \\
\hline UTM & Universal Transverse Mercator \\
\hline VIKOR & Vise Kriterijumska Optimizacija I Kompromisno Resenje \\
\hline WGS & World Geodetic System \\
\hline WLC & Weighted linear combination \\
\hline WHO & World Health Organization \\
\hline WP & Weighted Product \\
\hline
\end{tabular}




\section{INTRODUCTION}

Health care waste is defined as the total waste stream from a healthcare facility that includes both potentially infectious waste and non-infectious waste materials (WHO, 2005). Poor management of such waste can cause serious diseases to healthcare personnel and become a significant health risk to the population. Therefore it is imperative that the management of such waste streams are dealt with in a systematic and comprehensive manner.

The healthcare sector is intrinsically guided by values such as patient/personnel safety and service quality. However, in developing countries, such as Kenya, the extent by which these values are met are ultimately determined by fund availability. The government as well as the private sector often work with minimal budgets as they often have multiple other sectors competing for limited funds (Development \& Training Services, 2012). The consequence of this, is that, such fundamental values are implemented at a low scale, more so at government facilities. This implies that waste management and environmental issues are relegated to the periphery and are not prioritised.

No formal system with organized coordinated procedures are in place to manage waste. There is very little attempt by stakeholders to adhere to the regulations outlined by the Public Health Act and the National Environmental Management Agency (NEMA), Kenya's environmental regulatory body (Development \& Training Services, 2012).

A prevalent issue in most hospitals and primary healthcare facilities in Kenya is negligent dumping and uncontrolled burning of healthcare waste (National Aids and STI Control Programme, 2007); (Development \& Training Services, 2012). Healthcare waste in urban areas is commonly mixed and disposed off along with the general solid waste. In peri-urb an and rural areas, waste may be buried without treatment in an unlined pit (Bickel, 2007; Koros, 2014; WHO, 2005). Alternatively, where incinerators are non-existent or non-operative, medical waste may be burned in an open burn area (Development \& Training Services, 2012; WHO, 2005).

Incinerators, where available, are non-compliant with respect to both recommended national and international environmental regulations ( Ministry Of Health, 2015; WHO, 2004). According to a study carried out by USAID, an American humanitarian government agency, around $94 \%$ of the 111 health facilities in Kenya they visited, were non-compliant in how the incinerators were operated (Ministry Of Health, 2015). Similarly, it has been shown that most incinerators are poorly sited as they are too close to populated areas ( Development \& Training 
Services, 2012; Koros, 2014; Mazrui, 2010). This mismanagement bears risks for the staff, patients and communities to be exposed to serious biomedical hazards and environmental dangers.

Environmentally, incineration of healthcare waste is not the ideal solution for disposal. It is however the most viable option for developing countries. A research by Greenpeace Rese arch Laboratories documented a detailed report on the effects of incinerators on human health (Allsopp, Costner, \& Johnston, 2011). The most controversial issues are dioxin and furan emissions as well as the disposal of the remaining ashes. The dioxin and furan emissions occur through burning of chlorine-containing wastes. According to the World Health Organization, exposure to dioxins and furans is mostly through food intake (WHO, 2005). Therefore, contact between cultivated lands and waste from incinerators should be prevented.

With regards to the ash remains, there are two types, the fly ash from the air filtration equipment and the bottom ash that remain after incineration. These contain numerous hazardous chemicals, such as dioxins and heavy metals. Majority of the ash is landfilled or taken to municipal dumpsites (Koros, 2014; Allsopp, et al., 2011). This can result in contamination of sub-soils and groundwater. The contamination of groundwater by compounds that have leached from the waste, in particular, heavy metals like lead and cadmium from fly ash has been documented (Allsopp, Costner, \& Johnston, 2011).

Therefore, in situations where incineration presents itself as the best option, care needs to be taken to ensure that exposure to these toxic pollutants is reduced. One way in which this could be done is to ensure an incinerator facility is sited in less-densely populated areas and places where farming does not take place (WHO, 2004).

This study views central siting of an incinerator as a solution to three main problems. Firstly, it can be seen as a way of countering the cost constraint. Whereas, big hospitals may afford to buy and maintain incinerators, smaller hospitals and primary healthcare centres (PHCs) may be challenged by such an approach. Several health facilities of a given region could pool capital to invest in a modern incinerator. A logistic network may then be set up to collect waste on a daily basis from each facility. Secondly, regarding environmental pollution, a central incinerator, will provide hospitals and small scale PHCs an appropriate avenue to dispose of their waste safely. Thirdly, is the issue of monitoring and control. Having several health facilities with non-compliant incinerators would only contribute to more pollution and authorities will have more difficulty supervising them (Koros, 2014). On the contrary, a single large modern incinerator designed with modern emission control will help reduce pollution 
and additionally, such a centre could serve as an emission monitoring point for authorities (Koros, 2014).

When identifying suitable incinerator locations, economic, social and environmental factors need to be considered. Geographical Information Systems (GIS) techniques can be used to analyse these factors, integrate the information and identify candidate locations based on set parameters (Tavares, Zsigraiová, \& Semiao, 2011). The Multi-Criteria Decision Analysis (MCDA) tools can then be used to identify the best alternative by ranking them according to how they perform against a set of criteria (Achillas, Moussiopoulos, Karagiannidis, Banias, \& G.Perkoulidis, 2013).

The specific area of interest in this study is Kilifi county in the Coastal province of Kenya. Potential suitable locations to place a waste incinerator were identified using GIS techniques. MCDA methodologies were then applied to identify a location that is within a reasonable distance to several healthcare facilities and is also reasonably distanced away from largely populated areas. These were the two main criteria but several others were also considered.

\subsection{Study Area}

Kilifi County is one of the six counties in Coast region. The county lies between latitude $2^{\circ} 0^{\prime}$ and $4^{\circ} 0^{\prime}$ South, and between longitude $39^{\circ} 0^{\prime}$ and $400^{\circ} 14^{\prime}$ East. The county covers an area of $12,609.7 \mathrm{Km}$. It has six sub-counties namely Kilifi, Ganze, Malindi, Magarini, Rabai and Kaloleni (Kilifi County, 2013).

The population of the county was $1,109,735$ according to the 2009 population census, of which $74.3 \%$ of the population lives in rural areas and $25.7 \%$ lives in urban areas (Kilifi County, 2013). The county has nine level 4 public hospitals, 20 level 3 public health Centres, 197 level 2 public dispensaries, one mission hospital, two private hospitals, one armed forces hospital, five private nursing homes and 107 private clinics (Kilifi County, 2013).

The entire road network covers about $3000 \mathrm{Kms}$. Of this $1,320 \mathrm{~km}$ is rural classified network, about $450 \mathrm{~km}$ is national classified network and the rest are unclassified. Approximate $30 \mathrm{~km}$ of rural county roads are bitumen standards, $220 \mathrm{Km}$ of rural county roads are gravelled and the rest are earth roads (Kilifi County, 2013). This is important to consider in the context of siting a central incinerator as accessibility to the road network is an important criteria. 
With regards to ingestion of food being the primary source of exposure to dioxins and furans, one must take into account arable land versus non-arable land while considering siting an incinerator. This is especially so, since the county government plans to develop the agric ultural sector in the county as envisioned in its strategic goals. The county's arable land is estimated to be approximately $6,891.2 \mathrm{~km}^{2}$ with a non-arable land of $5,407 \mathrm{~km}^{2}$. This indicates that 56 percent of the land is useful for agriculture (Kilifi County, 2013).

\subsection{Problem Statement}

The problem this study tries to address is the rampant poor handling and mismanagement of healthcare waste across most hospitals in Kenya. The main contributing factors are as follows:

- Lack of proper treatment and disposal facilities.

- General lack of a properly enforced system, whether at hospital/PHC level or county administrative level to manage such waste.

- A compounding factor of lack of investment funds to acquire suitable and necessary equipments.

- Recent studies have proven that available incinerators are often poorly sited either being too close to high density populated areas or being too close to farms and water bodies.

\subsection{Significance of Study}

This study suggests that establishing a central medium sized modern incinerator will help achieve the following:

- Several hospitals and PHCs can pool their individual funds and thus, they can collectively afford a compliant incinerator. This can help overcome the issue of investment cost.

- Hospitals and especially small scale PHC, will be able to dispose of their waste in a safer, more environmentally conscious technique as currently, many simply either bury their waste in unlined pits or burn the waste openly.

- Lack of pollution monitoring and regulation compliance will easily be addressed, as having a single facility as opposed to multiple facilities will enable regulatory bodies, such as NEMA, to supervise operations carried out at the facility. 
- Reduction of mixing infectious healthcare waste with general municipal waste thus reducing risks of infections.

\subsection{Aims of Study}

This study's main aim was to identify a suitable location for placing a medical incinerator plant in Kilifi county of the Kenyan Coast province. This was achieved by meeting the following goals:

- Identifying a comprehensive and relevant set of criteria that was used to compare different feasible locations

- Assigning appropriate weights to individual criterion by reviewing previous assignment of weights in past literature.

- Applying spatial analysis and decision making analysis to identify the most suitable location.

\subsection{Site Selection Methodology}

Site selection requires consideration of a comprehensive set of factors and balancing of multiple objectives in determining the suitability of a particular area. Siting an incinerator requires a reliable evaluation process that should identify the best possible location. This location must comply with governmental regulations while, at the same time, minimizing economic, environmental, health, and social costs. The methodology used is as described:

The technique was in two stages. Firstly, a spatial analysis using a GIS tool was carried out to identify some of the feasible incinerator locations. This was based on a set of spatial criteria developed to select possible locations. The criteria were weighted using the MCDA tool, Analytic Hierarchy Process (AHP). Secondly, an evaluation and ranking of the feasible locations was conducted using other MCDA tools to select one or more specific sites.

A brief description of GIS and MCDA tools will be provided.

\subsubsection{Geographical Information Systems (GIS)}

Geographic information systems (GIS) are computer-based tools for capturing, storing, manipulating, analysing and displaying spatial data. They have emerged as an important tool for land use suitability analyses and are recognized in terms of reducing both time and cost 
(Malczewski, 2004). GIS is used to select optimal sites for various waste management facilities such as landfills and waste treatment plants. Most of these applications benefit from the map overlay GIS functions and spatial allocation modelling methods. The identification of an optimal site requires the integration of various environmental, social and economic data as well as complicated technical and legal parameters. These parameters are usually individually represented as thematic maps in the GIS. These are then superimposed and the final output is the suitability map of the area under investigation. A large fraction of these applications produce binary outputs while most recent ones aim at evaluating a "suitability index" as a tool for ranking of the most suitable areas (Kontos, Komilis, \& Halvadakis, 2005). The suitability map could then be the core of a spatial decision support system for a landfill site / waste treatment facility selection problem (Christos \& Katia, 2011).

\subsubsection{Multi-Criteria Decision Analysis (MCDA)}

MCDA is a science that facilitates in the decision making process. It considers multiple criteria in decision-making environments. Decision making problems are complex in that they are characterized by conflicting attributes such as cost, performance, reliability, safety, productivity and affordability. In the presence of multiple criteria, a unique optimal decision for the problem does not exist but rather many or even infinitely many decisions are suitable. In such a scenario, MCDA assists the decision maker in selecting the best alternative from the number of feasible choices under the presence of multiple criteria (Achillas, Moussiopoulos, Karagiannidis, Banias, \& G.Perkoulidis, 2013).

MCDA is increasingly being employed to tackle waste management problems. Increased availability of techniques and technologies for dealing with waste management is giving rise to a spectrum of alternatives of solution approaches. Selecting an efficient solution requires considering several differing parameters and factors in different contexts. MCDA provides a tool that allows decision makers to evaluate the different alternatives against the set of factors and weigh them objectively, but still in a customizable frame that considers every unique context ( (Achillas, Moussiopoulos, Karagiannidis, Banias, \& G.Perkoulidis, 2013).

\subsubsection{Spatial Multi-Criteria Decision Analysis (SMCDA)}

SMCDA is a GIS-based MCDA. It is a process that combines and transforms spatial and aspatial data (input) into a resultant decision (output) (Malczewski, 2004). In contrast to conventional MCDA analysis, spatial multi-criteria analysis requires information on criterion values and the geographical locations of alternatives in addition to the decision makers' preferences with respect to a set of evaluation criteria. This means analysis results depend not only on the 
geographical distribution of attributes, but also on the value judg ments involved in the decision making process. The procedures involve the utilization of geographical data, the decision maker's preferences and the manipulation of the data and preferences according to specified decision rules. Accordingly, two components are significant for spatial MCDA: the GIS component and the MCDA component. These two components then combine the geographical data and the decision maker's preferences into unified and meaningful set of alternative decisions (Malczewski, 2004). SMCDA provides an efficient and systematic approach to tackling land-use suitability problems, such as siting problems. 
This page has been left blank intentionally. 


\section{LITERATURE REVIEW}

GIS and MCDA tools have been used extensively in studies related to finding a location for undesirable facilities. An undesirable facility is one which people want located far away from their area (Tang, Boyer, Pedram, Yusuff, \& Zulkifli, 2013). These facilities include landfills and treatment plants such as incinerators. Majority of the studies focus on landfill siting. Below is a briefing of some of the studies.

Eskandari et. al suggest a methodology to select a landfill site in Marvdasht city. The study was based on simultaneous consideration of environmental, economical and socio-cultural criteria. They utilized GIS and AHP to identify a suitable location. AHP was used to weight the criteria. Sub-criteria weighting were performed by the rank ordering method. In this method, all factors were placed in a rank-order (most important item at the top). From this rank-order the numerical weights were calculated, using either the expected value method (e.g. economical criteria) or the rank sum method (e.g. environmental and socio-cultural criteria). The uniqueness of their study is in the fact that the siting task was first evaluated under three separate visions, each time placing more importance to each criteria grouping. This was due to conflicting opinions among expertise and stakeholders. The results were crossed referenced with a fourth map that was prepared by assigning equal weights to all groups of criteria. They conclude that assignment of equal weighting does not lead to the most suitable location identification (Eskandari, Homaee, Mahmoodi, Pazira, \& Genuchten, 2015).

Tavares et. al. perform a study to locate an incinerator in the high density populated island of Santiago, Cape Verde. They proposed a two-scale approach due to starting with a large area. The first applied scale, the global scale, initially screened the studied area identifying suitable inter-municipal zone(s) satisfying the most relevant socio-economic, technical and environmental requirements. Then, in the second scale, the local scale, a more detailed evaluation of the previously identified zones was performed. The local scale comprised of two phases. In Phase 1 a detailed suitability ranking was performed locally within the identified area by combining non-environmental feasibility factors. In Phase 2 , the local scale procedure ranks identified areas from phase 1 in terms of their environmental impact performance. They further carried out a sensitivity analysis, considering six scenarios. They concluded the results were strong since areas that had the best attributes (higher grades) were almost independent of changes in the weights associated with selected decision criteria (Tavares, Zsigraiová, \& Semiao, 2011).

Rikalovic et. al. propose a clearly outlined model optimized and adapted for industrial site selection. Again it is a GIS based MCDA model with two phases: The site screening phase and the site evaluation phase. The developed model, structures the decision making process into ten 
steps. It generates alternatives and assesses them using GIS and MCDA methods. The two MCDA tools they used were AHP and Weighted Linear Combination (WLC). They argue that such a model allows for the efficient resolution of a complex problem such is industrial site selection. Optimizing the number of criteria and alternatives, standardization of criterion scores and making suitability map for each criterion gives the opportunity to perceive each criterion separately and together through final suitability map (Rikalovic, Cosic, \& Lazarevic, 2014).

In a different study by Eskandari et. al., that argues against GIS usage in developing countries, a new quantitative landfill site selection method based on available soil classification maps is introduced. The authors argued that the method reduced the number of evaluation criteria, simplified the site selection process, and enhanced multiple applicability of the soil maps. They performed a case study for Marvdasht City in the centre of Fars Province, Iran. The approach involved two separate stages. First, necessary criteria for preliminary landfill siting were obtained from a land classification map initially prepared for irrigation purposes. Thereafter, the criteria were standardized using a rating approach and then weighted to obtain a suitability map for landfill siting. Since the method required only a limited number of evaluation criteria, the weighting method was relatively simple and compatible with existing weighting methods such as AHP or the use of the rank order scheme, Simple Additive Weight (SAW). The method seemed particularly attractive for developing countries often lacking adequate expertise and reliable data. Results were almost identical to those obtained with a more traditional environmental landfill siting approach (Eskandari, Homaee, Mahmoodi, Pazira, \& Genuchten, 2015).

Another study that was as well for landfill selection, was performed for Lake Beyşehir in Turkey. This was an important region because it is the largest freshwater and drinking water reservoir in Turkey. Accordingly, the main criteria and focus was on environmental aspects such as geology/hydrology, surface waters, protected areas and distance from settlements. Economic criteria were also considered. The authors weighted the criteria using AHP and respective criteria maps were generated. They used the equal interval classification method, thus the study area was classified into four groups of high, moderate, low and very low suitability, which covered $3.24 \%, 7.55 \%, 12.70 \%$ and $2.81 \%$ of the study area, respectively. They eventually narrowed down to two candidate sites from the high suitability areas (Sener, Sener, Nas, \& Karagüzel, 2010).

Rajamani's methodology to site an incinerator in Austin city was two-fold. First, a spatial analysis using GIS was done to zero in on some of the feasible incinerator locations. In this stage, a set of spatial criteria was developed to select possible locations. Then, GIS was used to deploy the criteria and come up with a choice set of feasible alternatives for siting the 
incinerator facility. In the second stage, a multi-criterion decision analysis was conducted with the feasible locations to select one or more specific sites. A set of economic and environmental criteria was developed and implemented as a linear optimization problem. Excel Solver was then used as an optimization tool to choose the best or most optimal alternative, given the set of objectives and constraints. Lastly, the solution was analyzed and compared under different constraints to demonstrate the logical correctness of the approach (Rajamani, 2002).

A pioneering two-layered Analytic Network Process (ANP) model to locate an undesirable facility was developed by Tuzkaya et. al.. The ANP model accommodated and incorporated interdependencies and feedback between decision attributes in a structured manner. This is unlike the classic MCDA methods which assume independence. The first layer of the model had two clusters and included a control hierarchy of criteria and sub-criteria. The goal was placed at the top of this hierarchy. The control criteria cluster, which was the third level cluster consisted of benefits, opportunities, cost and risks. These were weighed against the second level cluster, the main criteria cluster, consisting of social perception, environmental and national economy factors. All elements were paired with an upper level criterion in this level. The second layer of the model consisted of the sub-networks which represented the interactions between the clusters of alternatives and the criteria. A pair wise comparison was carried out and the model was solved and analyzed using the Superdecisions software 1.6.0. The results they state were not fully satisfactory to the decision makers, and suggest this may have been contributed by a data set that was not coherent. Nevertheless, they were able to achieve the principle objective of the study which was to use intangible data as well as the tangible to reach commonly acceptable and consistent results (Tuzkaya, Önüt, Tuzkaya, \& Gülsün, 2008).

Issa et. al. also researched on possible landfill sites in Abu Dhabi. They used a GIS-based MultiCriteria Evaluation System. The methodology they used is based on a composite suitability analysis using map overlays and their extension to include statistical analysis. The GIS integration model they used was based on Boolean operations. It involved the logical combination of binary maps resulting from the application of conditional operators. They used an index overlay method where each location was evaluated according to weighted criteria, resulting in a ranking on a suitability scale. Eight suitability criteria were used in the study. A map was created for each suitability criterion and a final composite map was finally produced by simple overlaying of the individual maps. The output was a binary map as each location was either satisfactory or not (Issa \& Shehhi, 2012).

Önüt et. al. try to select a trans-shipment site for waste management. They considered four waste groups: domestic solid waste, construction debris and rubble, medical solid waste and hazardous solid waste. They used five criteria based on interview with authorities. They also 
believed to identify a solid waste trans-shipment site, they needed to consider tangible and intangible conflicting criteria together. In this way they utilized a combination of AHP and fuzzy TOPSIS to measure weights of criteria and to locate a trans-shipment area for solid waste respectively (Önüt \& Soner, 2008)

A unique study by Cheng et. al. approached the landfill siting problem by integrating MCDA with Inexact Mixed Integer Linear Programming (IMILP). First, IMILP was used to determine the municipal waste flow at minimal total cost for each potential landfill site. The main results generated from the IMILP model were waste flow cost, the total cost, and the time period before development of a new landfill is needed. The total costs for the potential sites generated from the IMILP model served as input to the MCDA model. A set of MCDA methods were used to determine the best potential landfill site. Five MCDA methods were applied. These were the Simple Weighted Addition (SWA) method, Weighted Product (WP) method, Cooperative Game Theory(CGT ), TOPSIS, and Complementary ELECTRE. The results of the MCDA methods were then aggregated. The final ranking of the alternatives was considered reliable and adequately reflected consideration of the various criteria as well as the decision makers' subjective preferences (Cheng, Chan, \& Huang, 2003).

Milosevic and Naunovic present several improvements in the process of landfill site selection using the VIKOR compromise ranking method. They tried to evaluate the most favourable location for a sanitary landfill facility from three alternative locations. The aim of their article was to present several improvements in the practical process of landfill site selection using VIKOR. They integrated it with a novel approach to using a fuzzy AHP linear interpolation method for the calculation of the weighing coefficients. They argue that this integration ensures greater objectivity when assigning the weighting coefficients through the evaluation of criteria pairs. Also, the use of systematic application of interpolation, each pair can be properly evaluated (Milosevic \& Naunovic, 2013).

Another study by Ferreti, proposes a spatial multi-criteria approach for siting an MSW landfill in the Province of Torino (Italy). The study illustrates the development of a Decision Support System based on the integration of GIS and ANP. ANP was selected as it has the advantage of allowing a network model structuring. This the author argues is relevant when trying to reflect interdependencies between real-world elements as is the case with the factors that determine the land suitability to host an MSW landfill. Thus by using ANP the dependence relationships among the criteria can be assessed, and the relative importance of all the elements that play an influence on the final choice to be evaluated. The purpose of the study was to thus generate a suitability map of the area under analysis for locating a waste landfill, paying particular attention 
to the contribution that the spatial ANP offers to sustainability assessments of undesirable facilities (Ferreti, 2011).

Sumathi et.al. also address the siting of a new landfill in an urbanizing Indian city, Pondicherry. They used MCDA, specifically AHP, and overlay analysis using GIS. Their proposed system can accommodate new information on the landfill site selection by updating its knowledge base. Their main interest in using GIS, is that it can have a post-construction purpose for longterm monitoring of landfills. The system can help maintain account data to facilitate collection, operation and provide customer service. It can also be used to analyse optimal locations for transfer stations and plan routes for vehicles transporting waste to transfer stations and from transfer stations to landfills. Several criteria of economic, social and environmental significance were considered and respective thematic maps created. AHP was used to derive the relative importance weighting of each criterion. The thematic maps were then weighted and a GISbased overlay analysis was performed to identify the best site for the landfill, one which fulfilled all of the desired attributes. (Sumathi, Natesan, \& Sarkar, 2008).

In a case study on Penang and Kedah states, Zakaria et. al try to determine a suitable location for a hazardous waste disposal facility. AHP was used to assign weights for evaluation criteria which were used as input in GIS analysis. The two states were preliminarily selected as candidate sites because the waste generated from these two states were exceedingly high compared to surrounding states. Additionally, these two states were considered as strategically located between four other states in the northern region of Peninsular Malaysia. Thus siting the facility in either state would minimize the haulage distances from all states. The site selection model involved three steps namely, the preliminary analysis, multi-criteria evaluation, and identification of the most suitable site. The preliminary analysis involved creating constraint and factor maps. The second stage involved the aggregation of the factor maps based on grading values from ' 1 ' to '10'. Lastly, the final constraint map and final factor maps were combined to produce a suitability map. From this map suitable sites were identified (Zakaria, Abdullah, Ramli, \& Latif, 2013).

Arkkan et al. try to determine the most appropriate sold waste disposal methodology for Istanbul, Turkey. They considered 8 cost criteria and 10 benefit criteria to compare between the following methodologies: ordered sorting, composting, biomethanization, bioethanol/biodiesel, burning, gasification, plasma, pyrolysis, FFW and biodrying. Three MCDM tools were used to evaluate which method is most appropriate. They are TOPSIS PROMETHEE and fuzzy TOPSIS. They implemented the MCDM models using SETED 1.0, a decision support software. The best selected methodology amongst all three MCDM tools was ordered sorting. The main reason for this according to the authors is that, according to 
experts, ordered sorting is already widely used in Istanbul (Arıkan, Şimşit-Kalender, \& Vayvay, 2017).

Another study by Bosompen et al consider siting waste transfer stations in Kumasi Metropolitan Area. They argue there is a need for these transfer stations in an urban setting as there is a difficulty of locating suitable land areas to be used as landfills. This is due to an increase in the quantity of municipal solid waste generated as a result of population growth in most urban areas. The Kumasi Metropolitan Area, which has an engineered landfill, is faced with the problem of waste collection from the generation centres to the final disposal site. Thus in their study, weighted linear composition, which was incorporated into GIS was used to determine potential waste transfer station sites. The key result established 11 sites located within six different sub-metros. Their result could be used by decision makers for site selection of the waste transfer stations after taking into account other relevant ecological and economic factors (Bosompem, Stemn, \& Fei-Baffoe, 2016).

Lastly, Tsiko's study explores the applicability and capability of solving site location problems using an integrated approach that includes the Markov-chain based Simulated Annealing (SA) algorithm, Geographic Information System (GIS), fuzzy Analytic Hierarchy Process (AHP) and Evaluation of Mixed Data (EVAMIX). The approach is applied to a multiple objective decision problem of selecting the best location for a new landfill site, which will serve Blantyre City, Malawi. The proposed methodology's novelty is in its capability to combine the flexibility of fuzzy logic in handling uncertainty with the simplicity, easy implementation and independence offered by simulated annealing in solving non-linear optimization problems, thus providing good site location solutions without losing consistency. In addition, the EVAMIX approach provides complete flexibility in using both quantitative and qualitative criteria. The methodology was able to provide 7 alternative landfill sites ranked form best to worst (Tsiko, 2016).

In conclusion, it can be observed that in most of the GIS-based works, the site rankings are performed in the integral decision making modules available in the GIS software. It was also observed that AHP was the primary method used to calculate criteria weights. 


\section{MULTI_CRITERIA DECISION ANALYSIS}

In decision theory, MCDA refers to methodologies used to support decision making in scenarios that offer multiple alternatives in the face of several and possibly conflicting criteria .

The decision-making processes can roughly be broken down into the following series of steps (Tzeng \& Huang, 2011)

Step 1: Defining the nature of the problem.

This involves identifying the set of criteria and how the problem can be modelled.

Step 2: Constructing the decision makers' preferences.

This involves collection of data or information useful for preference evaluation.

Step 3: Identifying the alternatives.

A set of alternative solutions to the problem are identified

Step 4: Evaluating the alternatives

This step involves selecting the appropriate evaluation model and obtaining the relative weights and performance score of each criteria with respect to each alternative.

Step 5: Determining the best alternatives.

The performance scores for each alternative are aggregated and the one with the best score is selected.

There are several MCDA methods that are used in practise. They can be categorised according to the method of operation according to Kangas et al. (2001a) and Martel (1998) as cited by Hyde (2006). They can be categorised as follows:

\section{- Value and utility-based methods:}

The value and utility-based methods are founded on Bernoulli's utility theory. These are evaluated against a utility function, where the best alternative with the highest utility value is determined (Tzeng \& Huang, 2011). Examples of such methods include AHP, ANP, SAW, TOPSIS, VIKOR.

\section{- Outranking methods:}

The outranking methods on the other hand, compare the preference relations among alternatives to acquire information on the best alternative rather than constructing complex utility functions (Tzeng \& Huang, 2011). Such methods include the set of Elimination and Choice Expressing Reality methods (ELECTRE) and the set of Preference Ranking Organization Method for Enriching Evaluations (PROMETHEE). 


\section{- Interactive approach methods}

These methods include the Step Method (STEM) and Interactive Multiple Goal Programming (IMGP) (Martin et al.,1999 as cited by Hyde, 2006)

In the context of MCDA, AHP and the relaxed ANP are not solely used to evaluate and rank alternatives but are also employed as the primary tools to determine the relative importance of criteria. They are used to derive the relative weights of criteria using pairwise comparisons between criteria. AHP is used in a hierarchical system, whereas ANP is used is a network designed problem (Tzeng \& Huang, 2011).

The following is a summary presentation of some of the above mentioned MCDA methods.

\subsection{The Analytic Hierarchy Process (AHP)}

AHP, developed by Thomas Saaty, provides a framework for the modelling and quantitative analysis of multiple criteria decision problems. It structures the problems into a hierarchical relationship based on the decision makers' priorities. These priorities are broken down into goals, criteria, respective sub-criteria and decision alternatives, each representing different levels in the hierarchy (Figure 3.1). The decision criteria at each level are subjected to a pair-wise comparison for assessing the relative importance between them. These comparisons are based on a 9 grade numerical scale, where the method systematically moves through all pair-wise comparisons of criteria and alternatives. The results are then compiled into a ratio matrix. Ultimately, scores are developed from the performance of alternatives with respect to an individual criterion and aggregated into an overall score (Tzeng \& Huang, 2011).

The 9 grade scale used is shown in the table below (Tzeng \& Huang, 2011):

Table 3.1 AHP's 9-Grade Scale

\begin{tabular}{|c|c|}
\hline Grade & Level of Importance \\
\hline 1 & Equal Importance \\
\hline 3 & Moderate \\
\hline 5 & Strong \\
\hline 7 & Determined \\
\hline 9 & Extreme \\
\hline $2,4,6,8$ & Intermediate Values \\
\hline
\end{tabular}


The steps of AHP are as follows (Tzeng \& Huang, 2011)

Steps 1: The problem is decomposed into a hierarchy of interrelated elements.

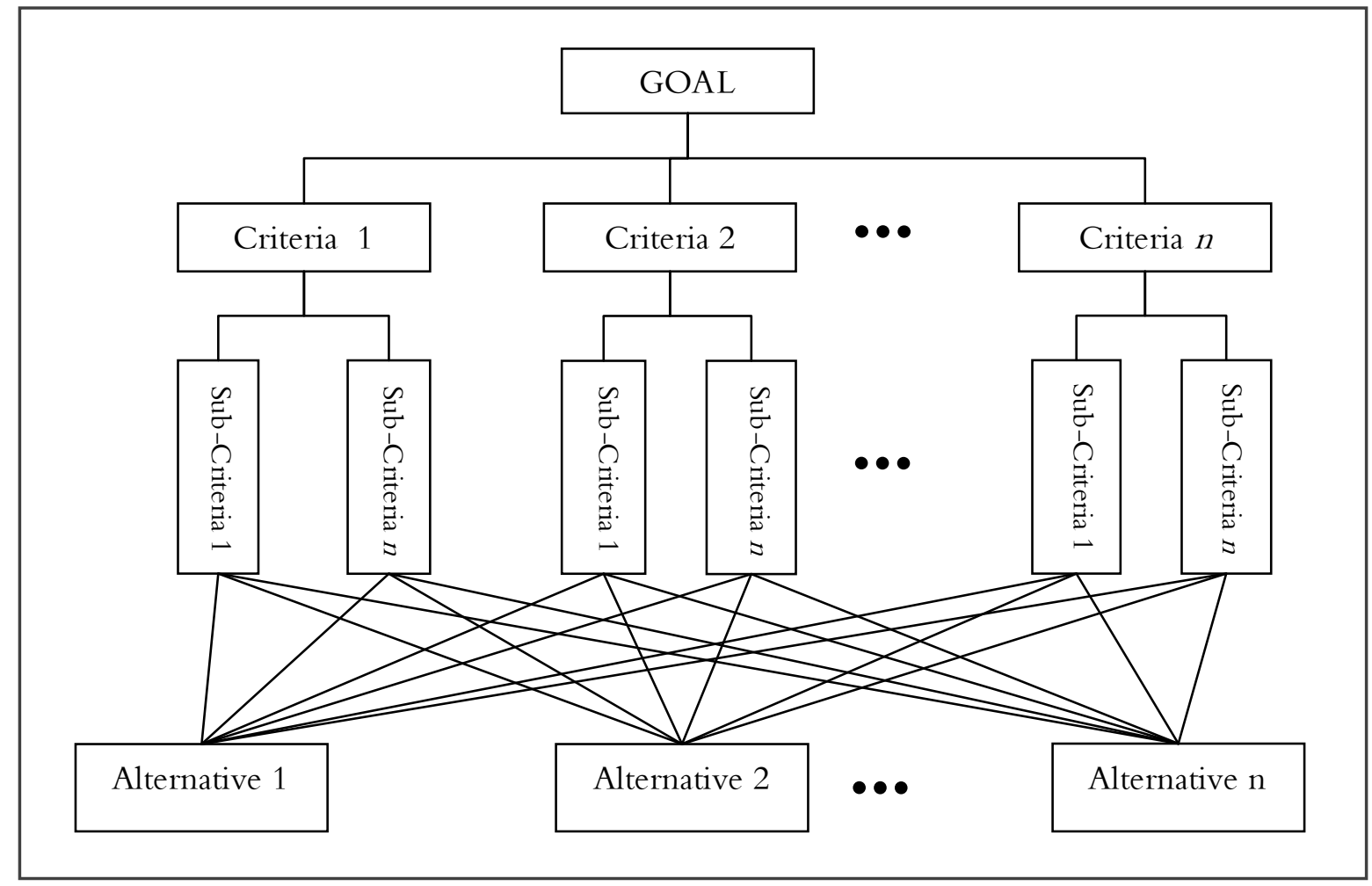

Figure 1 AHP Hierarchy

Step 2: For each level in the hierarchy, establish the reciprocal matrix by finding the relative weights of the criteria;

Step 3: Normalize the reciprocal matrices and find the relative weights of each criteria;

Step 4: Aggregate the relative weights of the criteria to determine the best alternatives/strategies.

The reciprocal matrix formed through a pair-wise comparison is carried out at each level of the hierarchy by establishing an $n \times n$ pair-wise comparison matrix $\boldsymbol{A}$ where $n$ represents the number of criteria in that level. Given that $a_{i j}$ represents the element $(i, j)$ in the matrix, the matrix is populated as follows:

- Fill all the elements of the diagonal $a_{i i}$ with 1 .

- For each criterion in row $i(i=1,2, \ldots, n)$, grade it relative to each of the other criteria represented by the $n$ columns using the 9-grade scale described previously.

- For every $a_{i j}=k$, fill $a_{j i}=1 / k$. 
Since the weights given to criteria are based on the decision makers' subjective judgement, a consistency ratio (CR) is calculated to determine the coherency and accuracy of the weights . This ratio is required to be below 0.1 for a reliable result and at most 0.2 for a tolerable result (Tzeng \& Huang, 2011). It is calculated using two other indices: the consistency index (CI) and the random consistency index $(\mathrm{RI})$ as shown below:

$$
C R=\frac{C I}{R I}
$$

Where CI and RI are given by

$$
C I=\frac{n_{\max }-\mathrm{n}}{n-1} \quad R I=\frac{1.98(n-2)}{n}
$$

The value $n_{\max }$ refers to the largest eigen value for the respective matrix $A$ and $n$ is the number of criteria.

\subsection{TOPSIS}

The Technique for Order Preference by Similarity to Ideal Solution (TOPSIS) was developed by Hwang and Yoon and based on finding a compromise solution (Tzeng \& Huang, 2011). Its basic concept is that the selected alternative should have the shortest distance from the ideal solution and the farthest distance from the negative-ideal solution. A Euclidean distance approach is used to evaluate this distance. A preference order of alternatives is yielded by ordering the relative distances of the different alternatives.

Four pieces of information are considered: the set of alternatives $A=\left\{a_{i} \mid i=1,2, \ldots, m\right\}$, the set of criteria $g=\left\{g_{j} \mid j=1,2, \ldots, n\right\}$, the set of performance ratings $X$ and the set of weights $W=\left\{w_{j} \mid j=1,2, \ldots, n\right\}$. The set $X$ represents the performance of each alternative against a specific criteria. The set $W$ represents the weights of the criteria. Given the ab ove information, the procedure of TOPSIS is summarized in the following steps (Triantaphyllou, Shu, Sanchez, \& Ray, 1998): 
Step 1. Calculate the Normalized Decision Matrix $R$

Given $m$ number of criteria and $n$ number of alternative, $R$ is a $m x n$ matrix populated with the normalized values $r_{i j}$. These values are calculated as shown below:

$$
r_{i j}=\frac{x_{i j}}{\sqrt{\sum_{i=1}^{m} x_{i j}}}
$$

Step 2. Calculate the Weighted Normalized Decision Matrix $V$

The set of criteria weights $W$ is accommodated into the decision matrix $R$ by performing the following calculation:

$$
v_{i j}=\left(w_{j}\right)\left(x_{i j}\right) \quad i=1, \ldots, m \text { and } j=1, \ldots n
$$

Where $w_{j}$ is the weight of the $j$ th attribute and $\quad \sum_{j=1}^{n} w_{j}=1$

Step 3. Determining the positive ideal point $\left(\mathrm{A}^{+}\right)$and the negative ideal point $\left(\mathrm{A}^{-}\right)$

In this step, the decision maker determines two values: $\mathrm{A}^{+}$the most preferable solution from the set of alternatives and $\mathrm{A}^{-}$is the least preferable alternative.

For the set of benefit criteria $J$, the decision maker wants to have a maximum value among the alternatives. For the cost criteria, the decision maker wants to have a minimum value among alternatives.

$$
\begin{aligned}
& A^{+}=\left\{\mathrm{v}_{1}^{+}, \mathrm{v}_{2}^{+}, \ldots, \mathrm{v}_{\mathrm{n}}^{+}\right\}=\left\{\left(\max _{\mathrm{i}} \mathrm{v}_{\mathrm{ij}} \mid \mathrm{j} \in \mathrm{J}\right),\left(\min _{\mathrm{i}} \mathrm{v}_{\mathrm{ij}} \mid \mathrm{j} \in \mathrm{J}^{\prime}\right), \mathrm{i}=1,2, \ldots, \mathrm{m}\right\} \\
& A^{-}=\left\{\mathrm{v}_{1}^{-}, \mathrm{v}_{2}^{-}, \ldots, \mathrm{v}_{\mathrm{n}}^{-}\right\}=\left\{\left(\min _{\mathrm{i}} \mathrm{v}_{\mathrm{ij}} \mid \mathrm{j} \in \mathrm{J}\right),\left(\max _{\mathrm{i}} \mathrm{v}_{\mathrm{ij}} \mid \mathrm{j} \in \mathrm{J}^{\prime}\right), \mathrm{i}=1,2, \ldots, \mathrm{m}\right\}
\end{aligned}
$$

Step 4. Calculating the Separation Measure

The separation distance of each alternative to the positive ideal solution and negative ideal solution are then calculated using the following formulas:

$$
\begin{array}{ll}
S_{i}^{+}=\sqrt{\sum_{j=1}^{n}\left(v_{i j}-v_{j}^{+}\right)^{2}} & \mathrm{i}=1,2, \ldots, \mathrm{m} \\
S_{i}^{-}=\sqrt{\sum_{j=1}^{n}\left(v_{i j}-v_{j}^{-}\right)^{2}} & \mathrm{i}=1,2, \ldots, \mathrm{m}
\end{array}
$$


Step 5. Calculating the Relative Closeness to the Ideal Solution

The relative closeness of each alternative relative to the ideal solution is calculated as follows:

$$
C_{i}=\frac{S_{i}^{+}}{S_{i}^{+}+S_{i}^{-}} \quad \mathrm{i}=1,2, \ldots, \mathrm{m} \quad 0 \leq C_{i} \leq 1
$$

Step 6. Rank the Preference Order

The relative closeness values are then ranked. The best alternative has the shortest $C_{i}$ value.

\subsection{VIKOR}

Vikor, Vise Kriterijumska Optimizacija I Kompromisno Resenje, is a compromise ranking method. A compromise ranking of alternatives is obtained by comparing a measure of closeness to the ideal solution. The multi-criteria measure for compromise ranking is developed from the $L_{p}$-metric used as an aggregating function in a compromise programming method (Opricovic \& Tzeng, 2004). Vikor has the following four steps (Opricovic \& Tzeng, 2004);

Given a set of possible alternatives $A=\left\{a_{i} \mid i=1,2, \ldots, m\right\}$ and a set of criteria $g=$ $\left\{g_{j} \mid j=1,2, \ldots, n\right\}$

Step 1: Determine the best value $f_{j}^{*}$ and worst value $f_{j}^{-}$for each criteria function:

If the $i$ th function criteria represents a benefit, then:

$$
f_{j}^{*}=\max _{i} f_{i j} \quad f_{j}^{-}=\min _{i} f_{i j}
$$

Else if the function represents a cost:

$$
f_{j}^{*}=\min _{i} f_{i j} \quad f_{j}^{-}=\max _{i} f_{i j}
$$

where $f_{i j}$ represents value of the $i$ th alternative for the $j$ th criteria. 
Step 2: Calculate the values of $S_{i}$, the utility measure and $R_{i}$, the regret measure by following equations:

$$
\begin{aligned}
S_{i} & =\sum_{j=1}^{n} w_{j}\left(f_{j}^{*}-f_{i j}\right) /\left(f_{j}^{*}-f_{j}^{-}\right) \\
R_{i} & =\max _{j} w_{j}\left(f_{j}^{*}-f_{i j}\right) /\left(f_{j}^{*}-f_{j}^{-}\right)
\end{aligned}
$$

Where $w_{j}$ is the weight of the $j$ th criteria

Step 3: Compute the values $Q_{i}$ by the relation

$$
Q_{i}=\frac{v\left(S_{i}-S^{*}\right)}{S^{-}-S^{*}}+\frac{(1-v)\left(R_{i}-R^{*}\right)}{R^{-}-R^{*}}
$$

Where $v$ is a weight for the strategy of maximum group utility, whereas $1-v$ is the weight of the individual regret and:

$$
\begin{aligned}
& S^{*}=\min _{i} S_{i} \quad S^{-}=\max _{i} S_{i} \\
& R^{*}=\min _{i} R_{i} \quad R^{-}=\max _{i} R_{i}
\end{aligned}
$$

Step 4: Rank the alternatives by sorting by the values $S_{i}, R_{i}$ and $Q_{i}$ in decreasing order. The results are three ranking lists.

Step 5: The best ranked alternative is the one with the lowest value of $Q_{i}$. This is so if the following two conditions are met:

- The alternative has an acceptable advantage. This advantage, the difference between the first alternative and second alternative values in the $Q_{i}$ ranking, should be greater than $1 /(m-1)$ where $m$ is the number of alternatives.

- The identified best alternative based on the lowest $Q$ value must aslo be the best ranked by $S$ and/or $R$.

If one of the conditions is not met then a set of compromise solutions is proposed. 


\subsection{PROMETHEE}

PROMETHEE refers to a set of methods that use an outranking principle to rank alternatives. They are based on the idea of a generalized criteria. These generalized criteria are used in a pair-wise comparison to pattern the relative importance of one alternative over another.

The difference between the methods is as follows (Tzeng \& Huang, 2011):

- PROMETHEE I method can provide the partial ordering of the decision alternatives;

- PROMETHEE II method can derive the full ranking of the alternatives;

- PROMETHEE III provides an interval order emphasizing indifference;

- PROMETHEE IV deals with continuous sets of possible alternatives.

- PROMETHEE V deals with segmentation constraints (Kazan \& Çiftci, 2013).

- PROMETHEE VI is concerned with representation of the human brain (Kazan \& Çiftci, 2013)

The main idea behind these methods is as described. Given a set of possible alternatives $A=\left\{a_{i} \mid i=1,2, \ldots, m\right\}$ and a set of criteria $g=\left\{g_{j} \mid j=1,2, \ldots, n\right\}$, then let $g_{j}\left(a_{i}\right)$ represents the performance of action $a_{i}$ with respect to the $j$ th criterion. The methods use a preference function, the generalized criteria $P_{j}(a, b)$ to compare alternatives. $P_{j}(a, b)$ is a function of the difference $d_{j}$ between any two alternatives for a specific criterion $j$ i.e $d_{j}=g_{j}(a)-g_{j}(b)$.

The detailed step-wise application of PROMETHEE is illustrated below:

Step 1: Determining the following information

- Weights of the criteria;

- Type of optimization for each criteria i.e. whether it should be maximised or minimized.

- The type of preference function $P_{j}(a, b)$ for each criteria with its respective $p, q$ and $\sigma$ values where applicable.

- $q$ is a difference threshold. It is the largest value of $d$ below which the decision maker considers there is indifference;

○ $p$ is a strict preference threshold. It is the lowest value of $d$ above which the decision maker considers there is strict preference; 
○ $\sigma$ is a well-known parameter directly connected with the standard deviation of a normal distribution.

Step 2: The difference $d_{j}$ is calculated by performing a pair-wise comparison between all pairs of alternatives $a$ and $b$ as shown below;

$$
d_{j}=g_{j}(a)-g_{j}(b)
$$

Step 3: The preference function $\operatorname{Pj}(a, b)$ determined in step 1 for a particular criterion is applied for each pair of actions. The six most popular functions are shown below (Tzeng \& Huang, 2011):

\section{Types of \\ Criteria}

Type I:

Usual criterion

\section{Analytical Definition}

$H(d)= \begin{cases}0, & d=0 \\ 1, & |d|>0\end{cases}$

Type II:

Quasi-criterion $H(d)= \begin{cases}0, & |d| \leq q ; \\ 1, & \text { otherwise. }\end{cases}$

Type III:

V-sharp

criterion

$$
H(d)= \begin{cases}\frac{|d|}{p}, & |d| \leq p, \\ 1, & |d|>0 .\end{cases}
$$

Type IV:

Level-criterion

$$
H(d)= \begin{cases}0, & |d| \leq q ; \\ 1 / 2, & q<|d| \leq p ; \\ 1, & \text { otherwise. }\end{cases}
$$
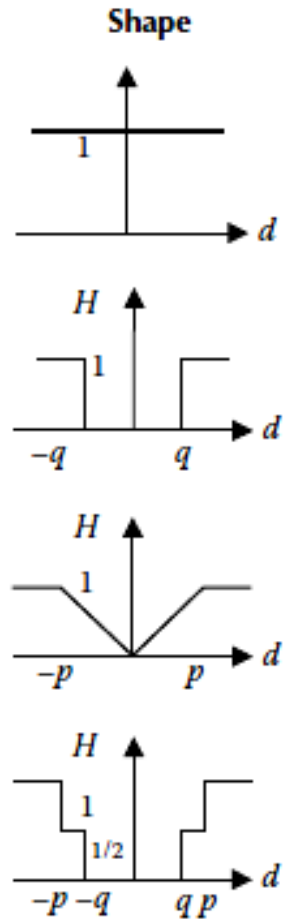

Type V:

Linear criterion

$$
H(d)= \begin{cases}0, & |d| \leq q ; \\ \frac{|d|-q}{p-q}, & q<|d| \leq p, \\ 1, & \text { otherwise. }\end{cases}
$$

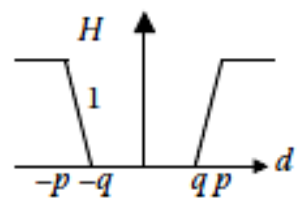

Type VI:

Gaussian criterion

$$
H(d)=1-\exp \left\{-\frac{d^{2}}{2 \sigma^{2}}\right\}
$$

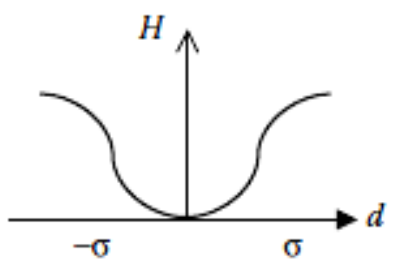

\section{Parameter}

$N A$

$q$

$p$

$q, p$

$q, p$

$\sigma$

Figure 2 Types of Generalized Criteria 
Step 4: The preference index $\pi(a, b)$ of every alternative $a$ over alternative $b$ is calculated. This index indicates the preference of alternative $a$ over $b$, all criteria being considered. It is calculated as shown below:

$$
\pi(a, b)=\sum_{\mathrm{j}=1}^{\mathrm{n}} \mathrm{W}_{\mathrm{j}} \mathrm{P}_{\mathrm{j}}(\mathrm{a}, \mathrm{b}) \quad \sum_{j=1}^{n} W_{j}=1
$$

Step 5: For outranking evaluations, the following values are calculated:

1) The leaving flow, which is the outranking power of alternative a.

$$
\emptyset^{+}(a)=\frac{1}{n-1} \sum_{b \in A} \pi(a, b), \quad b \neq a
$$

2) The entering flow, the outranked power of alternative a.

$$
\emptyset^{-}(a)=\frac{1}{n-1} \sum_{b \in A} \pi(b, a), \quad b \neq a
$$

3) The net flow

$$
\varnothing(a)=\emptyset^{+}(a)-\emptyset^{-}(a)
$$

The higher the leaving flow and the lower the entering flow, the better the alternative. These two values are used to induce a partial preorder, whereas the net flow is used for a complete preorder.

\subsection{ELECTRE}

This is a family of methods that use the outranking principle to rank a set of alternatives. There are several variants and they include Electre I, Electre II, Electre III, Electre IV, Electre IS, and Electre Tri (Whaiduzzaman, Gani, Anuar, \& Shiraz, 2014). The procedure sequentially reduces the number of alternatives during decision making. The basis of the methods' formulation is to sequentially select a smaller set of alternatives that are not only preferred over most of the criteria but also do not exhibit an unacceptable level of discontent for any criteria (Pohekar \& Ramachandran, 2004). 
The modelling of the preferences is based on the pair-wise outranking relations $S$. This relation determines whether one action $a$ is at least as good as another action $b$. Therefore, with such a comparison four scenarios may occur (Figueira, Mousseau, \& Roy, 2005):

4) $a S b$ and not $b S a$, i.e., $a P b$ ( $a$ is strictly preferred to $b$ ).

5) $b S a$ and not $a S b$, i.e., $b P a$ ( $b$ is strictly preferred to $a$ ).

6) $a S b$ and $b S a$, i.e., $a I b$ ( $a$ is indifferent to $b$ ).

7) Not $a S b$ and not $b S a$, i.e., $a R b$ ( $a$ is incomparable to $b$ ).

The relations between any two alternatives are assessed using two indices (Tzeng \& Huang, 2011):

1. The concordance index $(c(a, b))$ which is a measure of how much $a$ is at least as good as $b$.

2. The discordance index $(d(a, b))$ which is a measure of how $b$ is strictly preferred over a.

The outranking $a S b$ holds true if two conditions are met: firstly, a sufficient majority of criteria should be in favour of this assertion and if the concordance condition holds, none of the criteria in the minority should oppose too strongly to the assertion aSb (Figueira, Mousseau, \& Roy, 2005).

Below a detailed explanation of Electre I will be given. It is performed in two major steps: the building of the outranking relation and the exploitation of the outranking relation (Figueira, Mousseau, \& Roy, 2005).

\section{Step 1: Building the outranking relation}

Given a set of possible alternatives $A=\left\{a_{i} \mid i=1,2, \ldots, m\right\}$ and a set of criteria $g=$ $\left\{g_{j} \mid j=1,2, \ldots, n\right\}$, then let $g_{j}\left(a_{i}\right)$ represents the performance of action $a_{i}$ with respect to the $j$ th criterion.

Step 1a: Obtain weights for each criteria $g_{j}$ such that the sum of all weights is 1 .

Step 1b: For each ordered pair of alternatives, $(a, b) \in A$, calculate the concordance index $c(a, b)$ using the formula below. The values lie between 0 and 1 , which indicate the strength of the statement $a$ outranks $b$. 


$$
C(a, b)=\frac{\sum_{\forall j: g_{j}(a) \geq g_{j}(b)} w_{j}}{\sum_{j=1}^{n} w_{j}}
$$

Step 1c: For each ordered pair of alternatives, $(a, b) \in A$, calculate the discordance index $d(a, b)$ using the following formula.

$$
D(a, b)=0 \text { if } g_{j}(a) \geq g_{j}(b) \forall j
$$

Otherwise,

$$
\begin{aligned}
& D(a, b)=\frac{1}{\delta} \max _{j}\left[g_{j}(b)-g_{j}(a)\right] \\
& \delta=\max _{c, d, j}\left[g_{j}(c)-g_{j}(d)\right]
\end{aligned}
$$

Step 1d: Define a concordance threshold $\hat{c}$ and discordance threshold $\hat{d}$ such that $0<\hat{d}<\hat{c}<1$. With the combination of concordance and discordance indices for criterion $g_{j}$, an outranking relation can then be defined by the relation:

$$
a \text { Sb iff }\left\{\begin{array}{l}
c(a, b) \geq \hat{c} \\
d(a, b) \leq \hat{d}
\end{array}\right.
$$

\section{Step 2: Exploitation of the outranking relation}

The previous procedure does not necessarily identify a single preferred alternative, instead it defines a partial ordering on the set of alternatives. A smaller set of alternatives is identified such that any alternative not in the smaller set is outranked by at least one member of the set. Changing the concordance and discordance indices can change the number of elements of this smaller set. From this set a decision maker can decide on the best choice. At this point, a graph $G=(V, U)$, where $V$ is the set of vertices and $U$ the set of arcs can be constructed. The vertex represents an alternative $a \in A$. The arcs represent the relationship between two alternatives $a$ and $b$. An arc exists between the two alternatives (vertices) if $a$ is strictly preferred over $b$ or if $a$ is indifferent to $b$. If there is no arc between two alternatives, then the two are incomparable (Shofade, 2011). 


\section{GIS ANALYSIS}

\subsection{Suitability Analysis}

Below are the main steps involved in this analysis:

1. Identification of a set of relevant criteria. These were then arranged in a hierarchical structure and their relative weights calculated using AHP.

2. Collection of relevant data.

3. A pre-analysis of the data was carried out. This involved harmonizing the data into a uniform format.

4. An analysis of the prepared data involving Euclidean analysis, reclassification analysis and overlay analysis were performed.

A detailed breakdown of the above steps is given below:

\subsection{Criteria Identification}

The criteria identified in this study are shown in Figure 4.1. Eight criteria were considered in this study. These were categorized into three main groups: economic, environmental and social criteria.

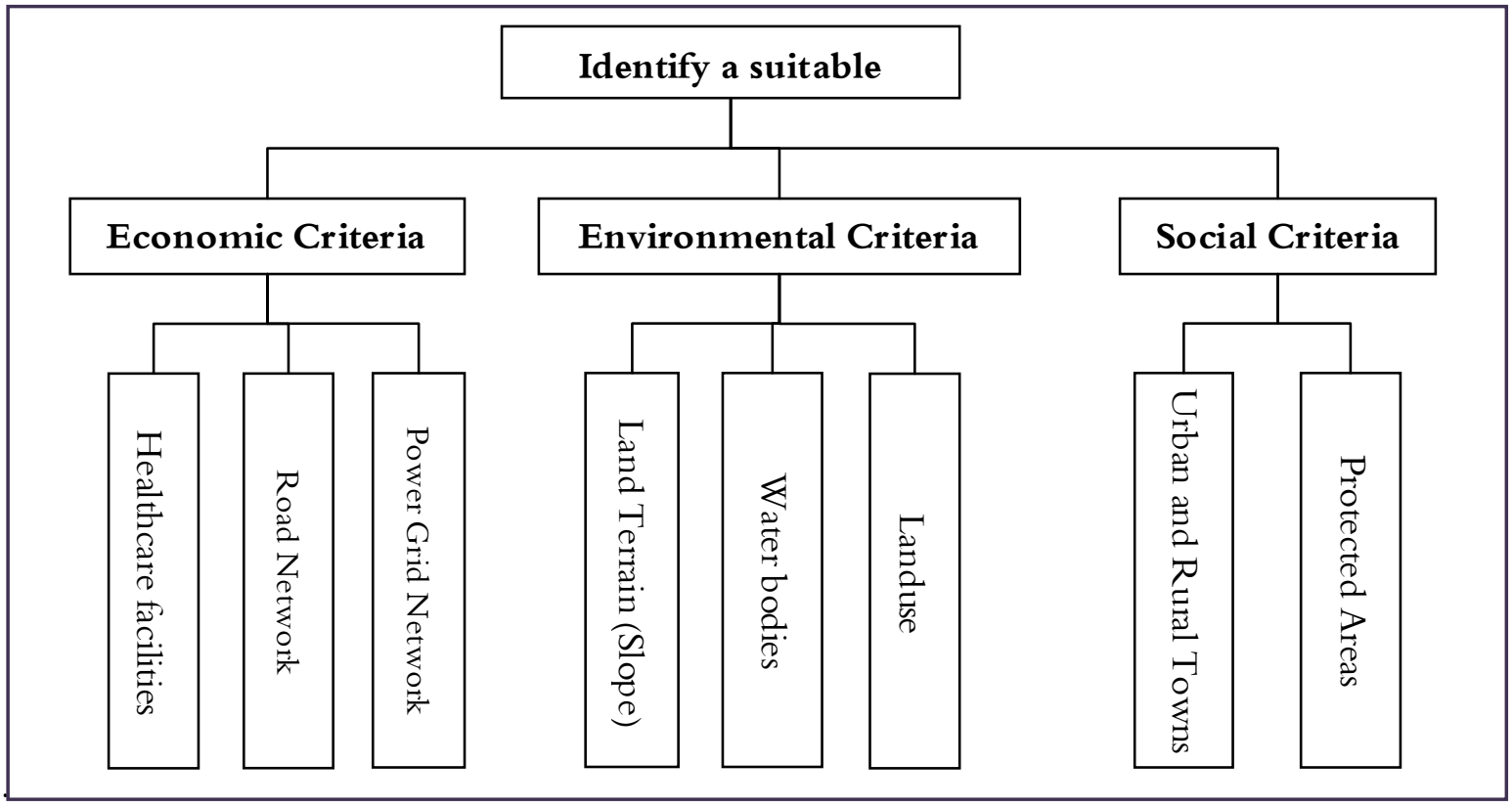

Figure 4:1 Criteria Hierarchy 


\subsubsection{Economic Criteria}

These criteria are concerned with the economic cost of setting up an incineration plant at a given location. The three criteria found to be relevant to this study are:

- Existing road network: If the plant is set up near the existing road network, the investment cost will be greatly reduced. However, having it too close to the road can be aesthetically displeasing. Therefore a buffer zone of $1500 \mathrm{~m}$ based on the work of Alzamili et al. (2015) was placed around the road network.

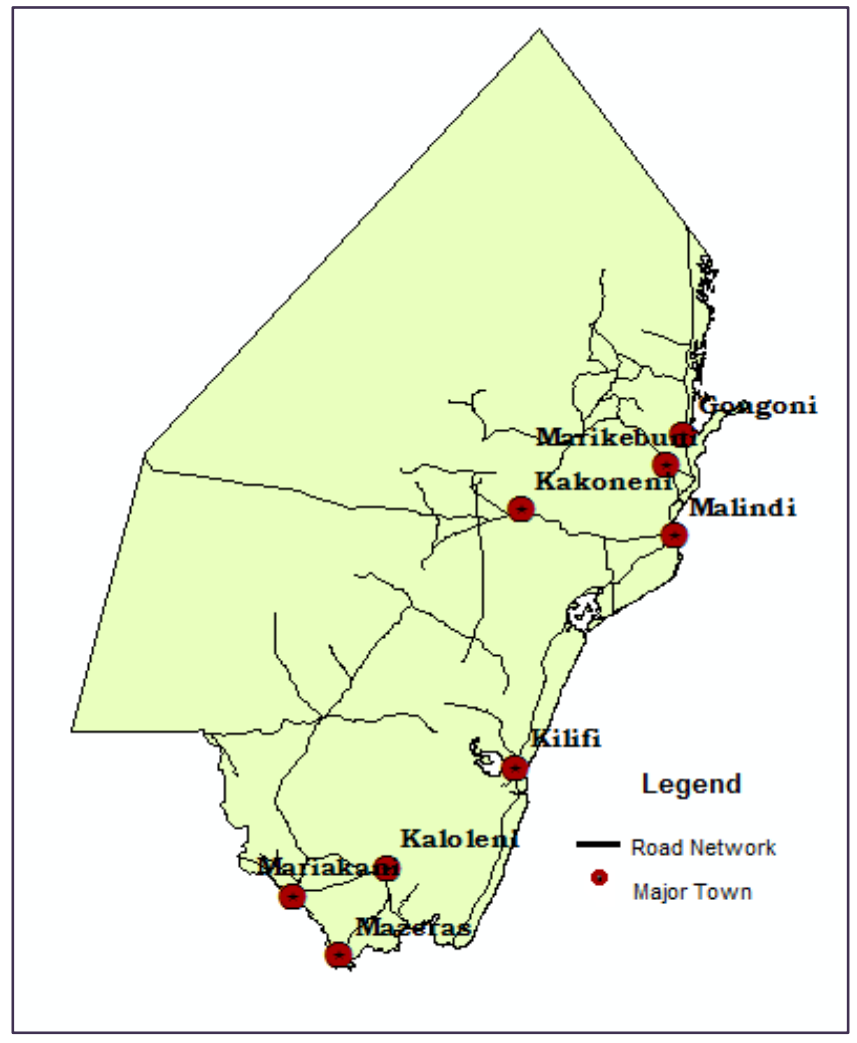

Figure 4:2 Road Network

- Existing electrical power grid network: Some rural and interior areas of Kenya are not connected to the national power grid. Therefore it is necessary to identify locations that have existing connections. Two types of information were used to analyse this. The locations of the existing low voltage gridline and the locations of transformers. When the two maps were overlaid, it was observed the transformer map had a wider coverage and included the low voltage gridline. Therefore to eliminate redundancy only the transformer location data was used. 


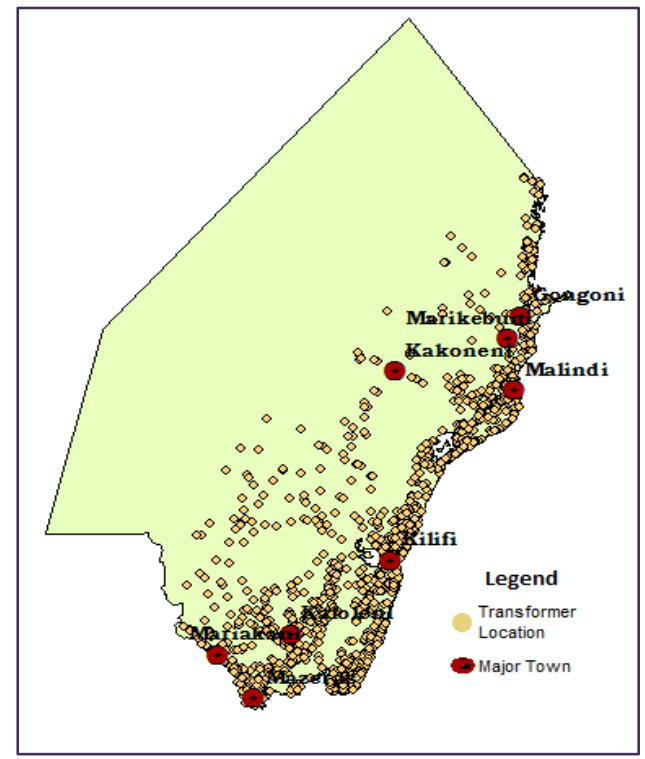

Figure 4:3 Power Grid Network

- Location of healthcare facilities: With regards to this criteria, two issues need to be considered. Firstly, is to find a location close to a health facility to reduce the logistical cost of transportation. Secondly, is to find a location that will be in close proximity to several healthcare facilities.

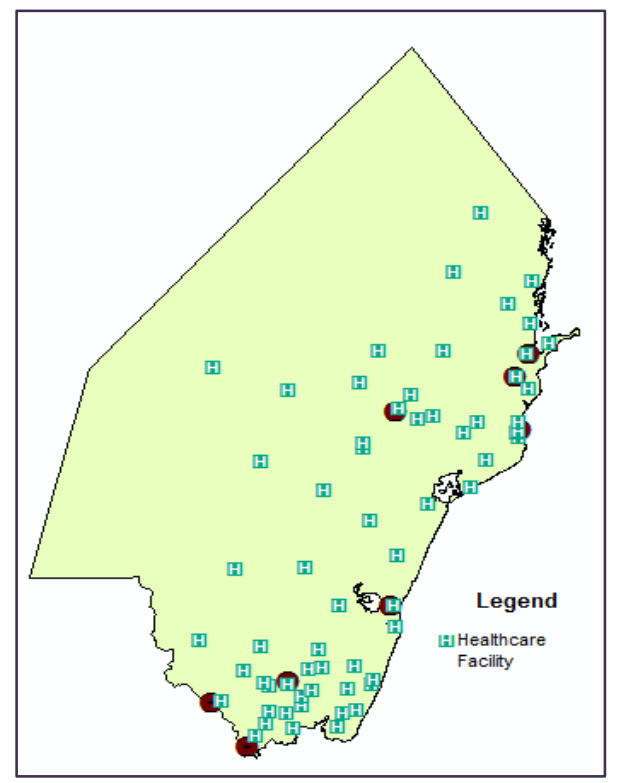

Figure 4:4 Healthcare Facilities Location

\subsubsection{Environmental Criteria}

The main issues raised against the construction of incinerators pertains to the pollution caused by such facilities (Allsopp, Costner, \& Johnston, 2011). The primary source of contamination is 
through food intake (WHO, 2005). Therefore it is paramount that the fly ash, bottom ash and other emissions do not come into contact with agricultural produce. The following sub-criteria were considered:

- Landuse: The area was classified according to the type of vegetation and agricultural potential of the land. The main categories identified were: agricultural lands, bushland, woodland, swamps, plantations, forest, and grassland. Majority of these are generally considered to be unsuitable for siting an incinerator, with respect to farming potential. Agricultural lands and grassland were considered of the lowest suitability because of the possibility of ingesting food that may be contaminated. The forest is also a low suitable area because it is a protected site. The swamp areas also, are not suitable as it would be dangerous to bury bottom ash and fly ash in wetlands. This is based on the presumption that the bottom ash will be buried in the same location as the incinerator. Therefore the only two area that are favourable are the bushlands and woodlands.

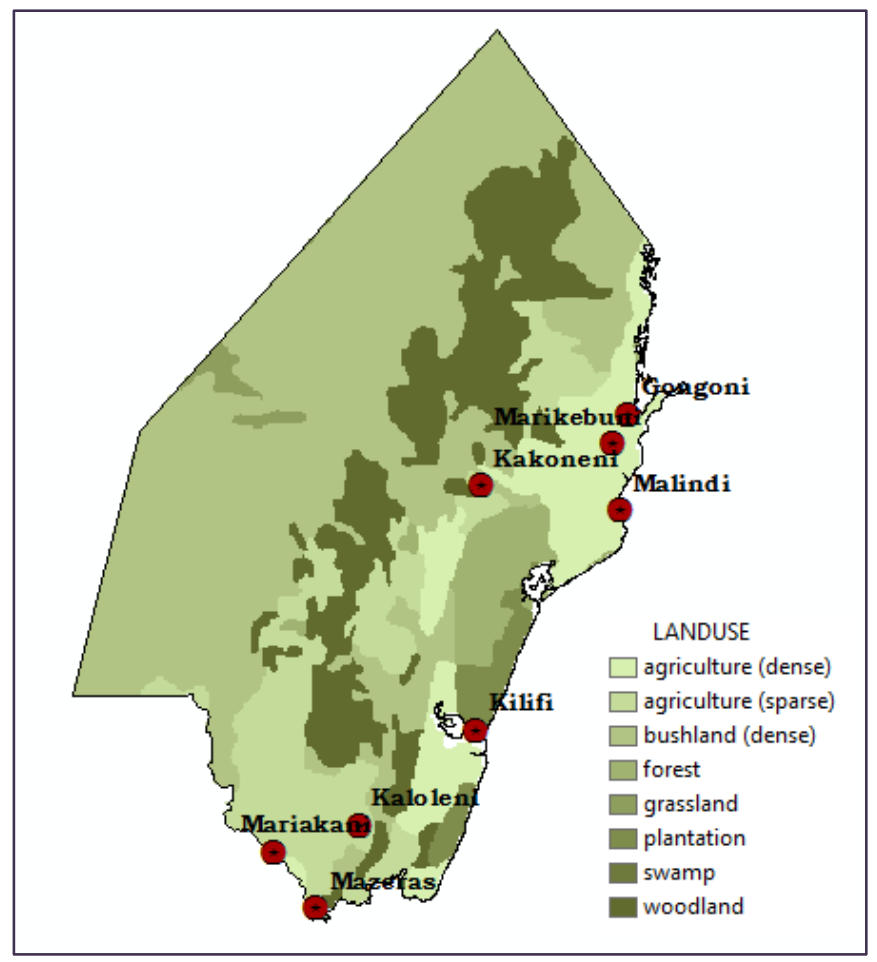

Figure 4:5 Landuse

- Rivers: Again, to minimise the risk of contaminating the rivers with buried incinerator waste, the goal is to identify a site that is reasonably far from the river banks. Generally all water bodies should have been considered rather than just the rivers. But after analysing the data, it was realised that the few water bodies that do exist, are along the 
rivers. These are: two dams and a few small seasonal lakes. Therefore it would be redundant to include a layer map for each of these water bodies.

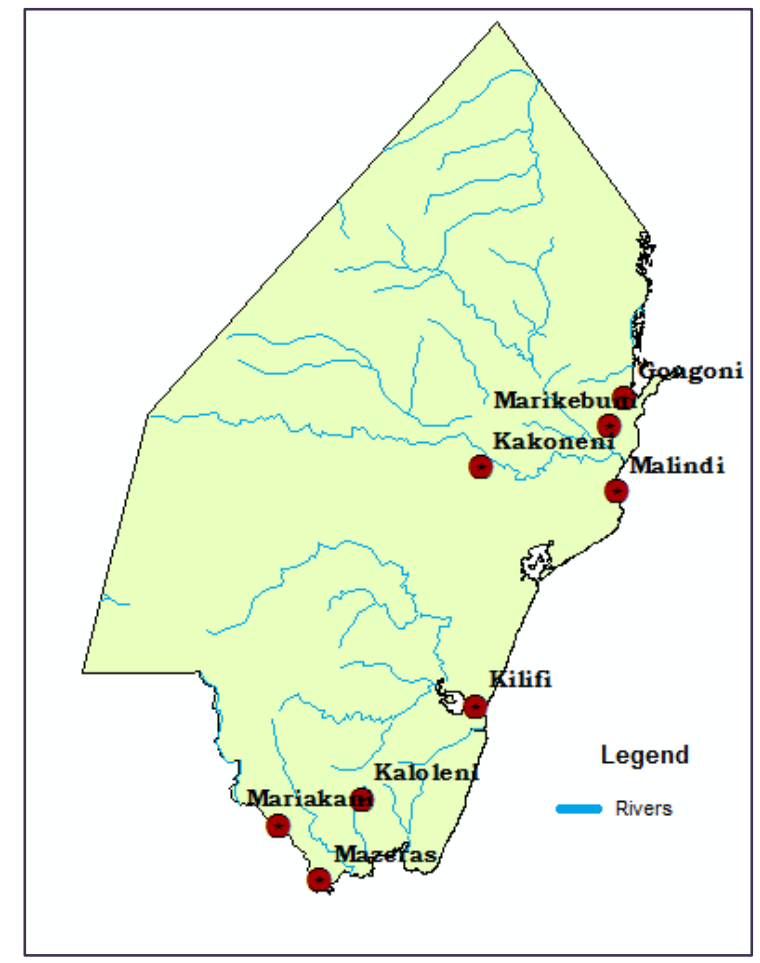

Figure 4:6 Rivers

- Terrain: Sites with steep slopes are generally unsuitable for siting an industrial facility like an incinerator (Tavares, Zsigraiová, \& Semiao, 2011). The surface water runoff and drainage in a high terrain area is higher due to the slopes and this can increase chances of contaminated water streaming to low terrain areas.

\subsubsection{Social Criteria}

- Proximity to Urban and Rural Towns: The larger the distance is away from these populated areas the better. Issues resulting from plant operations such as noise pollution, air pollution and possible environmental hazards must be considered (Tavares, Zsigraiová, \& Semiao, 2011). Furthermore, there is a natural aversion by communities to live in close proximity to such facilities. 


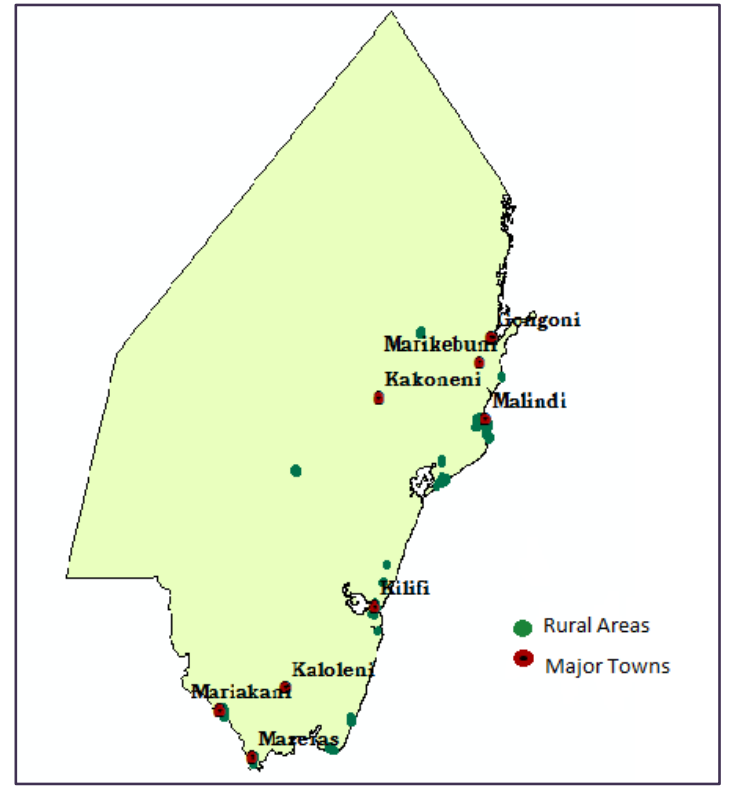

Figure 4:7 Rural Areas and Major Towns

- Protected Areas: Protected areas are nationally conserved areas. Therefore, construction of an incinerator in such an area and its environs is impossible (Tavares, Zsigraiová, \& Semiao, 2011).

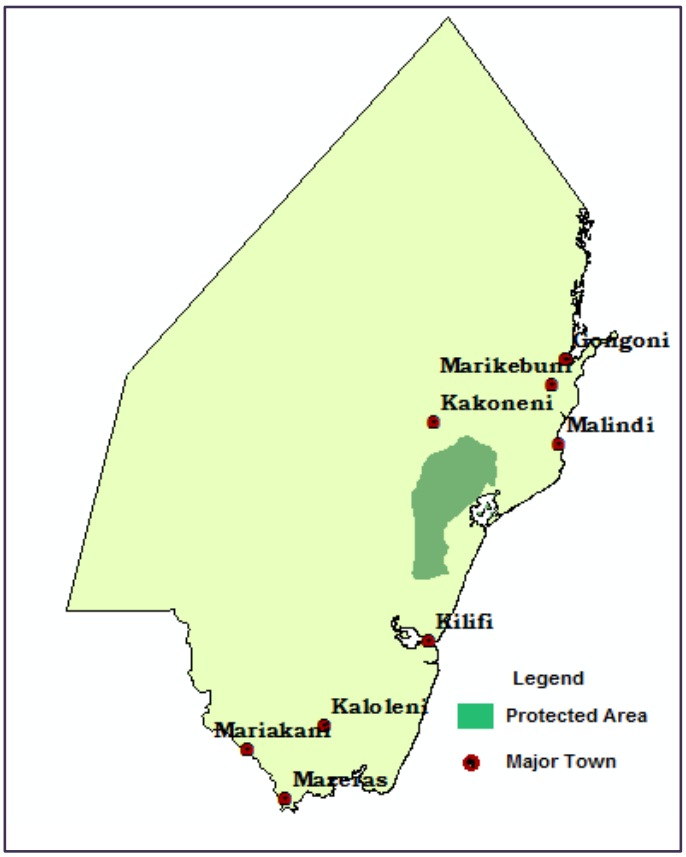

Figure 4:8 Protected Area 


\subsection{Weight Assignment}

The weights of the various criteria were determined as follows using AHP.

\subsubsection{Main Criteria}

This level consisted of economic (eco), environmental (env) and social (soc) criteria. The economic and environmental criteria were considered of equal importance. The social criteria was of least importance.

Table 4.1 First Hierarchy Comparison Matrices and Weights

\begin{tabular}{|c|c|c|c|c|c|c|c|c|c|c|c|c|}
\hline \multicolumn{4}{|c|}{ Comparison Matrix } & \multicolumn{8}{|c|}{ Normalization } & \multirow[t]{2}{*}{ Weight } \\
\hline & Eco & $\overline{\text { Env }}$ & Soc & & Eco & $\overline{\text { Env }}$ & Soc & & Eco & Env & Soc & \\
\hline Eco & 1 & 1 & 5 & Eco & 1 & 1 & 5 & Eco & $5 / 11$ & $5 / 11$ & $5 / 11$ & $45 \%$ \\
\hline Env & 1 & 1 & 5 & Env & 1 & 1 & 5 & Env & $5 / 11$ & $5 / 11$ & $5 / 11$ & $45 \%$ \\
\hline \multirow[t]{2}{*}{ Soc } & $1 / 5$ & $1 / 5$ & 1 & Soc & $1 / 5$ & $1 / 5$ & 1 & Soc & $1 / 11$ & $1 / 11$ & $1 / 11$ & $10 \%$ \\
\hline & & & & & $11 / 5$ & $11 / 5$ & 7 & & & & & \\
\hline
\end{tabular}

\subsubsection{Sub-Criteria}

Economic Criteria: The weights of road, grid and proximity to healthcare facilities (hf) were determined as shown.

Table 4.2 Economic Criteria Comparison Matrices

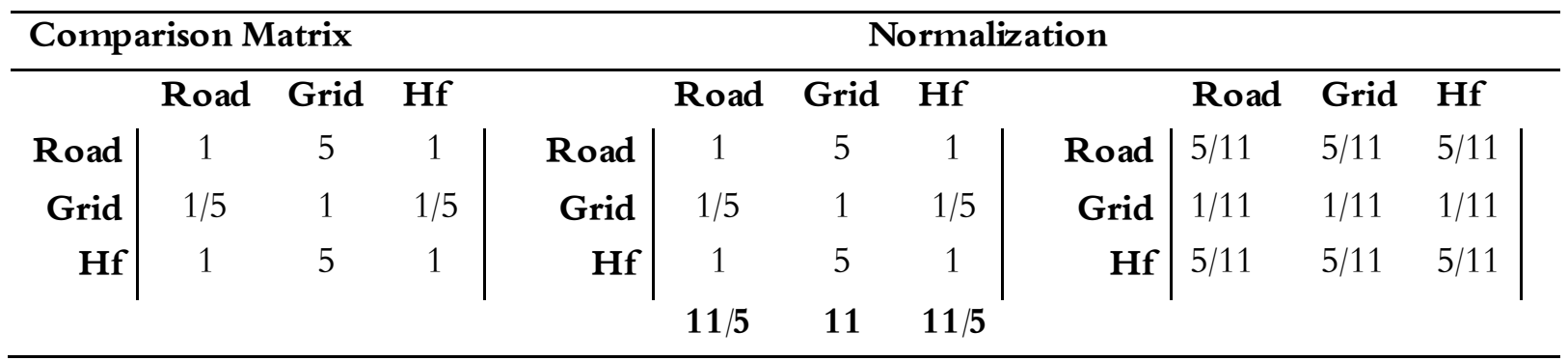

Table 4.3 Economic Sub-Criteria Weights

\begin{tabular}{c|c}
\hline Sub-Criteria & Weight \\
\hline Road & $45 \%$ \\
Grid & $10 \%$ \\
Hf & $45 \%$ \\
\hline
\end{tabular}


Environmental Criteria: The weights for terrain (ter), landuse (lu) and proximity to the river (riv) were determined as shown in the following table.

Table 4.4 Environmental Criteria Comparison Matrices

\begin{tabular}{l|ccc|c|ccc|c|ccc|}
\hline Comparison Matrix & \multicolumn{10}{c}{ Normalization } \\
\hline \multicolumn{3}{c}{ Ter } & Lu & Riv & \multicolumn{10}{c}{ Ter } & Lu & Riv & & Ter & Lu & Riv \\
Ter & 1 & $1 / 3$ & 1 & Ter & 1 & $1 / 3$ & 1 & Ter & $1 / 5$ & $1 / 5$ & $1 / 5$ \\
Lu & 3 & 1 & 3 & Lu & 3 & 1 & 3 & Lu & $3 / 5$ & $3 / 5$ & $3 / 5$ \\
Riv & 1 & $1 / 3$ & 1 & Riv & 1 & $1 / 3$ & 1 & Riv & $1 / 5$ & $1 / 5$ & $1 / 5$
\end{tabular}

Table 4.5 Environmental Sub-Criteria Weights

\begin{tabular}{c|c}
\hline Sub-Criteria & Weight \\
\hline Ter & $20 \%$ \\
Lu & $60 \%$ \\
Riv & $20 \%$ \\
\hline
\end{tabular}

Social Criteria: Here only two criteria were considered: proximity to urban and rural areas (ur) and proximity to protected area (pa). They were given equal weighting.

Table 4.6 Social Criteria Comparis on Matrices and Weight

\begin{tabular}{|c|c|c|c|c|c|c|c|c|c|}
\hline \multicolumn{3}{|c|}{ Comparison Matrix } & \multicolumn{6}{|c|}{ Normalization } & \multirow[t]{2}{*}{ Weight } \\
\hline & Ur & $\mathbf{P a}$ & & & $\overline{\mathbf{P a}}$ & & Ur & $\mathbf{P a}$ & \\
\hline Ur & 1 & 1 & $\mathbf{U r}$ & 1 & 1 & Ur & $1 / 2$ & $1 / 2$ & $50 \%$ \\
\hline \multirow[t]{2}{*}{$\mathbf{P a}$} & 1 & 1 & $\mathbf{P a}$ & & 1 & $\mathbf{P a}$ & $1 / 2$ & $1 / 2$ & $50 \%$ \\
\hline & & & & & 2 & & & & \\
\hline
\end{tabular}




\subsection{Data Collection}

Different datasets were used in the study. Majority of the datasets were downloaded from the World Resource Institute website. These include maps for the road network, protected areas, county administrative boundaries, major rivers, urban and rural areas. The information regarding land use was obtained from the Food and Agricultural Organization (FAO). The terrain imagery was obtained from Shuttle Radar Topography Mission (SRTM) data, downloaded from NASA's website. This provided the required digital elevation model for the study area. The maps for the electrical power grid network were obtained from Kenya Power and Lighting Company (KPLC), the main national transmitters and distributor of electricity. Finally, the healthcare facilities data set was downloaded from the Kenya Open Data Portal, an open source resource government website.

\subsection{Pre-Analysis}

The GIS software used to carry out the pre-analysis and analysis phases was ArcGIS 10.3. A consequence of obtaining the criterion maps from different sources was the non uniformity in its format. Therefore the pre-analysis stage involved the following processes:

- Converting vector maps to raster maps.

- Projecting the maps to a uniform coordinate system to enable compatibility during various analysis. The coordinate system the maps were projected to is the UTM coordinate system, zone 37S, WGS84 datum.

- Clipping all input data to Kilifi administrative area.

\subsection{Analysis}

This stage involved performing the following three analysis:

- Euclidean analysis

- Reclassification analysis

- Weighted overlay analysis

\subsubsection{Euclidean Analysis}

The Euclidian analysis involves determining the straight distance between each cell in a map and a determined source. It is calculated by obtaining the distance from the centre of a source cell to the centre of each surrounding cell. It does this by applying the Euclidean algorithm 
which works as follows: for each cell, the distance to each source cell is determined by calculating the hypotenuse using the difference between the $(x, y)$ coordinate values of the pair of cells on a two-dimensional scale (Alzamili, El-Mewafi, Besh, \& Awad, 2015). This analysis was performed for the following two sets of data based on suitability of an area from a given feature:

- Increased suitability based on close proximity to a feature:

From the set of criteria identified, the features that are advantageous to have close to a possible incinerator location are: roads, power grid network and healthcare facilities. Therefore with these features, land suitability increases the closer the area is to these features.

- Increased suitability based on remoteness of a feature

The criteria in this category include: distance to water bodies, specifically rivers in this study, distance to populated areas, both urban and rural areas and distance to protected areas. The further away these features are from an incinerator, the better.

Euclidian analysis was also performed on the terrain dataset. Generally the lower and flatter the area, the more suitable it is for an incinerator setup. Therefore, the resulting map graded low areas as being suitable.

The resulting maps from these analysis were raster maps, that classified the cells from the input maps based on their distance from the feature of interest. This analysis was carried out on each of the mentioned criterion data layer. The outputs are illustrated in the following pages with green areas indicating high suitability and red areas indicating low suitability: 


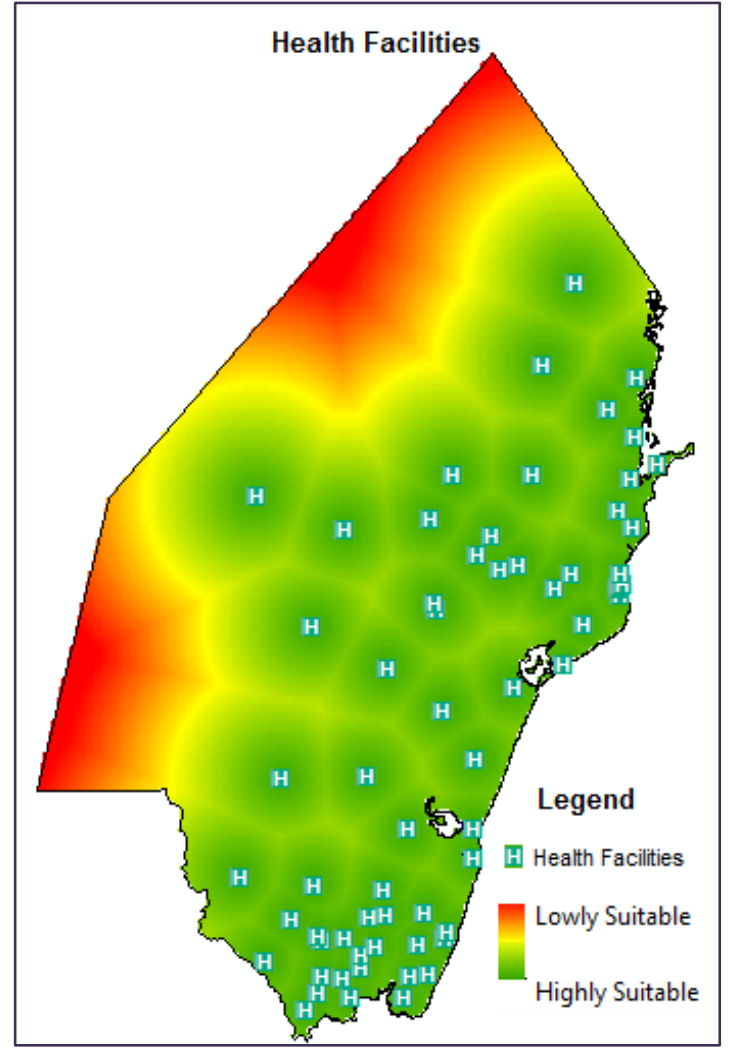

Figure 4:9 Distribution of Health Facilities

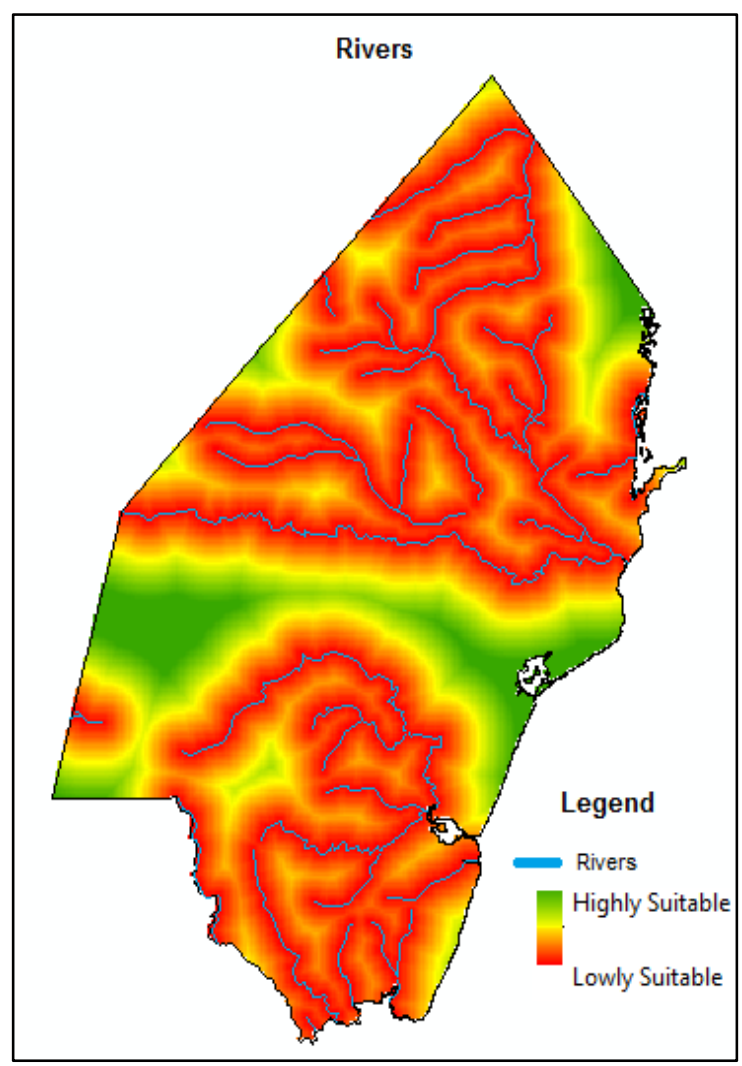

Figure 4:10 Distance from Rivers

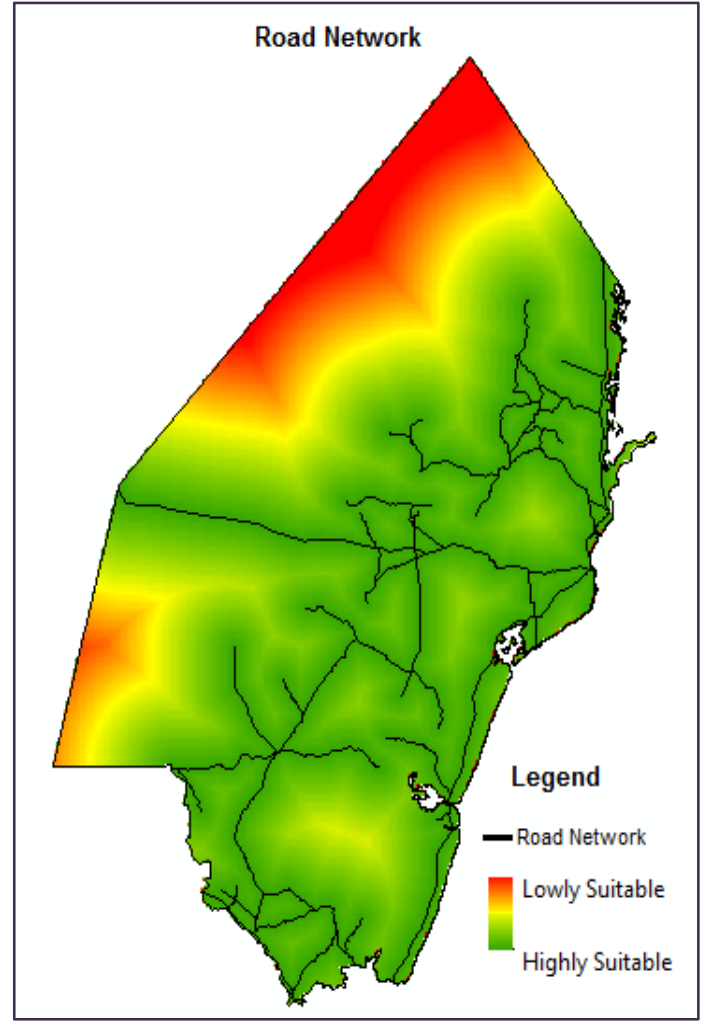

Figure 4:11 Distance from the Road Network

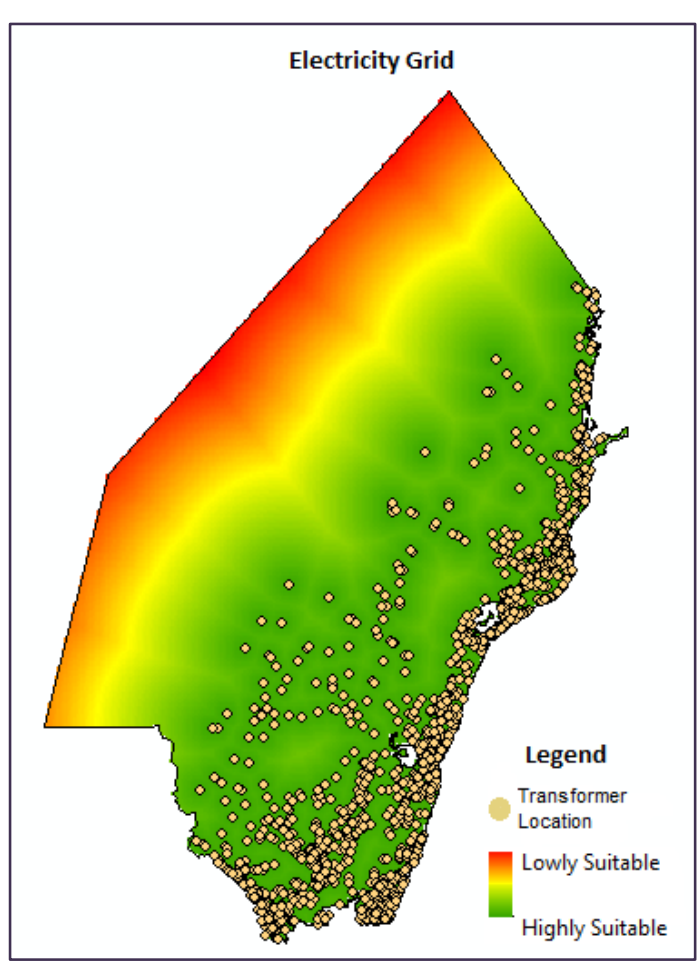

Figure 4:12 Distance from Electrical Grid Network 


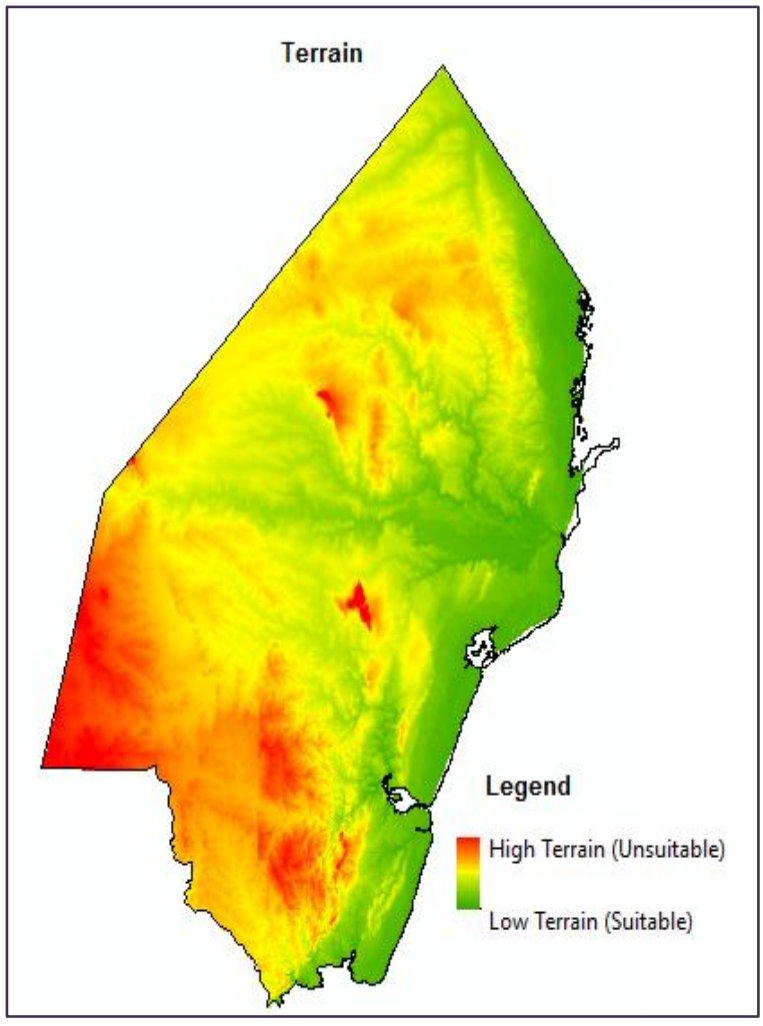

Figure 4:13 Area Terrain

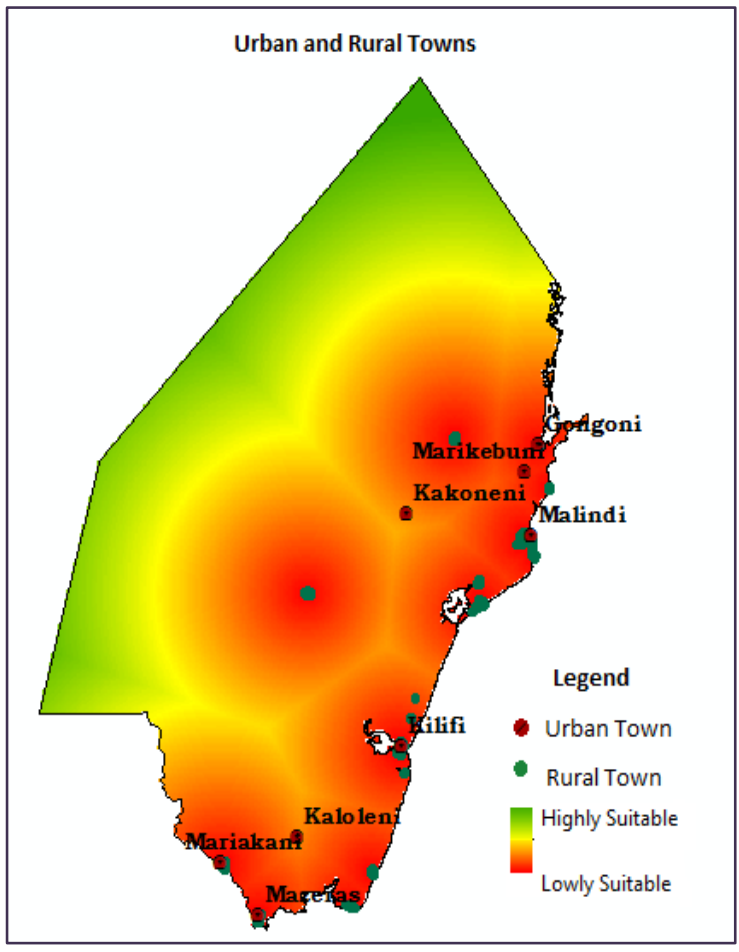

Figure 4:14 Location and Distance of

Urban-Rural areas

\subsubsection{Reclassification Analysis}

This phase regrouped the ranges of values generated in the Euclidian analysis into a single value. In this study the inbuilt quantile and natural break methods in ArcGIS were used to generate 9 classes. Each of these new groups were assigned a common score ranging from 1 to 9 . A score of 1 indicated least suitability, while a score of 9 indicated the highest suitability. These values were used in the overlay analysis. The reclassified data is shown in the following tables: 
Table 4.7 Urban Rural Reclassification

\begin{tabular}{rr|c}
\hline \multicolumn{3}{l}{ Distance in Metres } \\
\hline \multicolumn{1}{l}{ Start } & \multicolumn{1}{c}{ End } & Score \\
\hline 0 & 8454 & $\mathbf{1}$ \\
8454 & 14916 & $\mathbf{2}$ \\
14916 & 21389 & $\mathbf{3}$ \\
21389 & 28385 & $\mathbf{4}$ \\
28385 & 35928 & $\mathbf{5}$ \\
35928 & 43638 & $\mathbf{6}$ \\
43638 & 51216 & $\mathbf{7}$ \\
51216 & 60725 & $\mathbf{8}$ \\
60725 & 78565 & $\mathbf{9}$ \\
\hline
\end{tabular}

Table 4.8 River Reclassification

\begin{tabular}{rr|c}
\hline \multicolumn{3}{l}{ Distance in Metres } \\
\hline \multicolumn{1}{l}{ Start } & \multicolumn{1}{c}{ End } & Score \\
\hline 0 & 1615 & $\mathbf{1}$ \\
1615 & 3426 & $\mathbf{2}$ \\
3426 & 5258 & $\mathbf{3}$ \\
5258 & 7312 & $\mathbf{4}$ \\
7312 & 9417 & $\mathbf{5}$ \\
9417 & 11579 & $\mathbf{6}$ \\
11579 & 13949 & $\mathbf{7}$ \\
13949 & 16729 & $\mathbf{8}$ \\
16729 & 21242 & $\mathbf{9}$ \\
\hline
\end{tabular}

Table 4.9 Protected Areas Reclassification

\begin{tabular}{rr|c}
\hline \multicolumn{3}{l}{ Distance in Metres } \\
\hline \multicolumn{1}{l}{ Start } & \multicolumn{1}{c}{ End } & Score \\
\hline 0 & 7994 & $\mathbf{1}$ \\
7994 & 17573 & $\mathbf{2}$ \\
17573 & 26290 & $\mathbf{3}$ \\
26290 & 34355 & $\mathbf{4}$ \\
34355 & 42539 & $\mathbf{5}$ \\
42539 & 51326 & $\mathbf{6}$ \\
51326 & 62158 & $\mathbf{7}$ \\
62158 & 75837 & $\mathbf{8}$ \\
75837 & 98122 & $\mathbf{9}$ \\
\hline
\end{tabular}

Table 4.10 Terrain Reclassification

\begin{tabular}{rr|r}
\hline \multicolumn{3}{l}{ Height in Metres } \\
\hline Start & End & \multicolumn{1}{c}{ Score } \\
\hline-10 & 52 & $\mathbf{9}$ \\
52 & 101 & $\mathbf{8}$ \\
101 & 142 & $\mathbf{7}$ \\
142 & 175 & $\mathbf{6}$ \\
175 & 208 & $\mathbf{5}$ \\
208 & 248 & $\mathbf{6}$ \\
248 & 292 & $\mathbf{3}$ \\
292 & 367 & $\mathbf{2}$ \\
367 & 530 & $\mathbf{1}$ \\
\hline
\end{tabular}


Table 4.11 Healthcare Facilities

Reclassification

\begin{tabular}{rr|c}
\multicolumn{3}{l}{ Distance in Metres } \\
\hline \multicolumn{1}{l}{ Start } & \multicolumn{1}{l}{ End } & Score \\
\hline 0 & 4393 & $\mathbf{9}$ \\
4393 & 7812 & $\mathbf{8}$ \\
7812 & 11791 & $\mathbf{7}$ \\
11791 & 16635 & $\mathbf{6}$ \\
16635 & 21859 & $\mathbf{5}$ \\
21859 & 27303 & $\mathbf{6}$ \\
27303 & 32960 & $\mathbf{3}$ \\
32960 & 38844 & $\mathbf{2}$ \\
38844 & 47963 & $\mathbf{1}$ \\
\hline
\end{tabular}

Table 4.13 Landuse Reclassification

\begin{tabular}{l|c}
\hline Landuse & Score \\
\hline agriculture (dense) & $\mathbf{1}$ \\
agriculture (sparse) & $\mathbf{2}$ \\
plantation & $\mathbf{3}$ \\
forest & $\mathbf{4}$ \\
grassland & $\mathbf{5}$ \\
swamp & $\mathbf{6}$ \\
woodland & $\mathbf{7}$ \\
bushland (dense) & $\mathbf{8}$ \\
\hline
\end{tabular}

Table 4.12 Power Grid Reclassification

\begin{tabular}{rr|c}
\hline \multicolumn{3}{l}{ Distance in Metres } \\
\hline \multicolumn{1}{l}{ Start } & \multicolumn{1}{l}{ End } & Score \\
\hline 0 & 3270 & $\mathbf{9}$ \\
3270 & 7812 & $\mathbf{8}$ \\
7812 & 13493 & $\mathbf{7}$ \\
13493 & 19333 & $\mathbf{6}$ \\
19333 & 25155 & $\mathbf{5}$ \\
25155 & 30918 & $\mathbf{6}$ \\
30918 & 36618 & $\mathbf{3}$ \\
36618 & 42521 & $\mathbf{2}$ \\
42521 & 50879 & $\mathbf{1}$ \\
\hline
\end{tabular}

Table 4.14 Road Reclassification

\begin{tabular}{rr|c}
\hline \multicolumn{3}{l}{ Distance in Metres } \\
\hline \multicolumn{1}{l}{ Start } & \multicolumn{1}{l}{ End } & Score \\
\hline 0 & 1500 & $\mathbf{1}$ \\
1500 & 5823 & $\mathbf{9}$ \\
5823 & 9863 & $\mathbf{8}$ \\
9863 & 14535 & $\mathbf{7}$ \\
14535 & 19574 & $\mathbf{6}$ \\
19574 & 24794 & $\mathbf{5}$ \\
24794 & 30480 & $\mathbf{4}$ \\
30480 & 36704 & $\mathbf{3}$ \\
36704 & 47614 & $\mathbf{2}$ \\
\hline
\end{tabular}




\subsubsection{Weighted Overlay Analysis}

The various layers together with their weights were overlaid using the weighted overlay tool and resulting suitability maps were generated. The weighted overlay analysis method requires that every criterion be reclassified into a common scoring scale, as was previously done in the reclassifying analysis. This is because the tool works only with integer input raster files.

The overlaying was done in two phases:

- Phase 1: Each major criteria economic, environmental and social had its respective sub-criteria overlaid independently.

- Phase 2: The three resulting raster maps from the previous phase were then overlaid together and a final suitability map was generated.

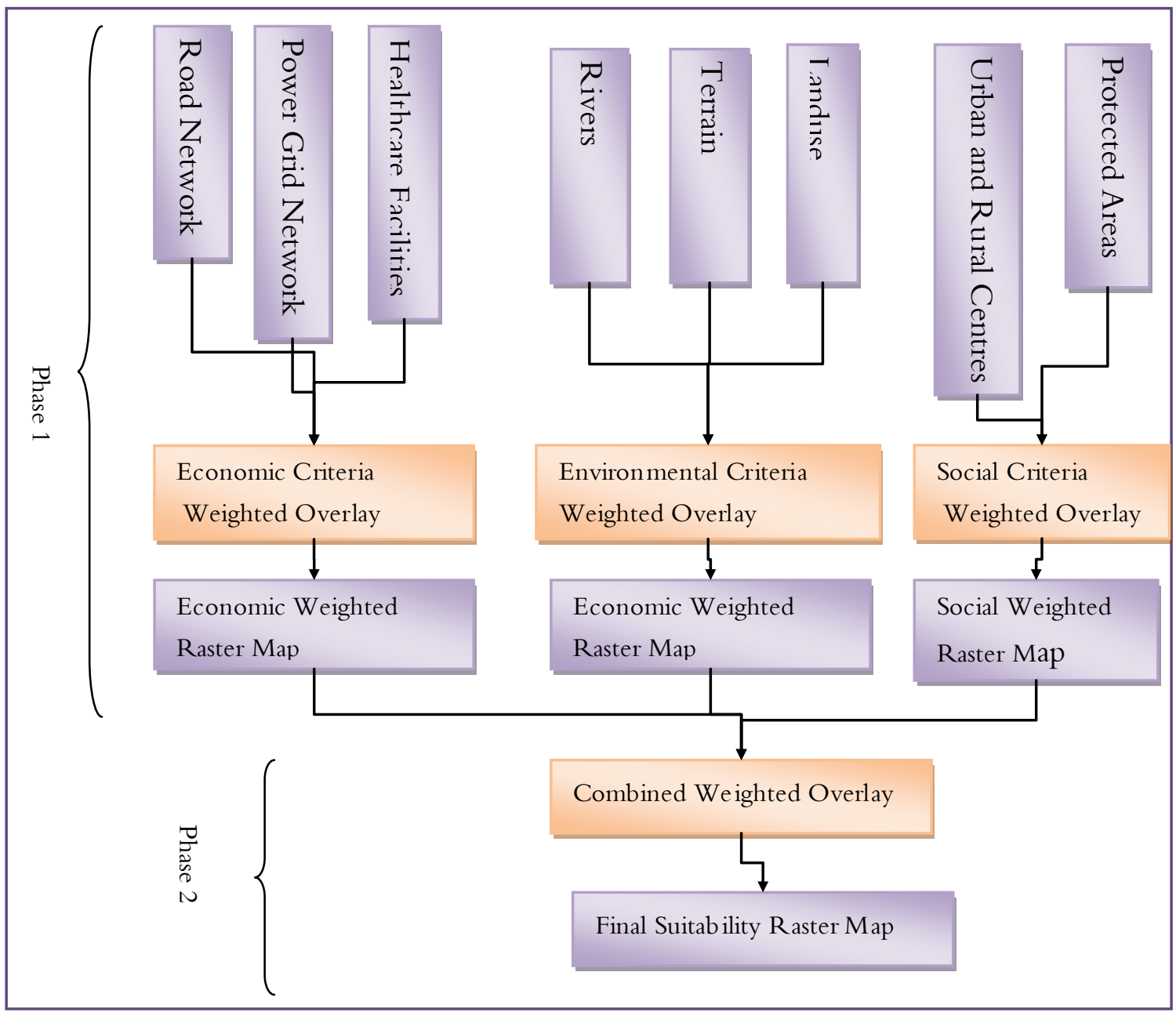

Figure 4:15 Weighted Overlay Flowchart 
The resulting maps are shown below:

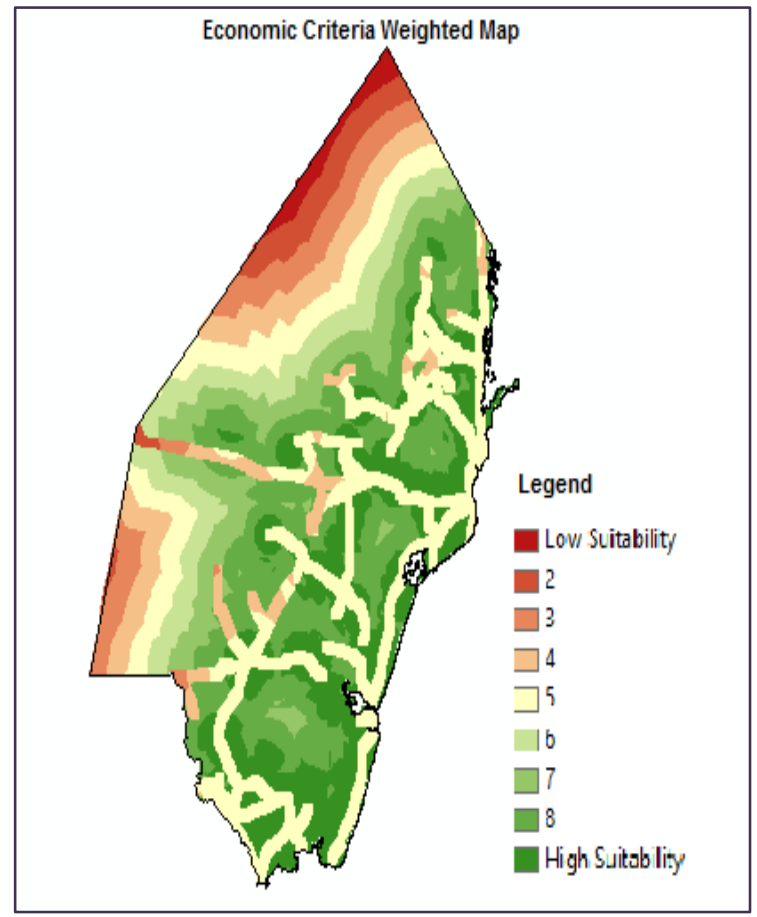

Figure 4:16 Economic Criteria Suitability Map

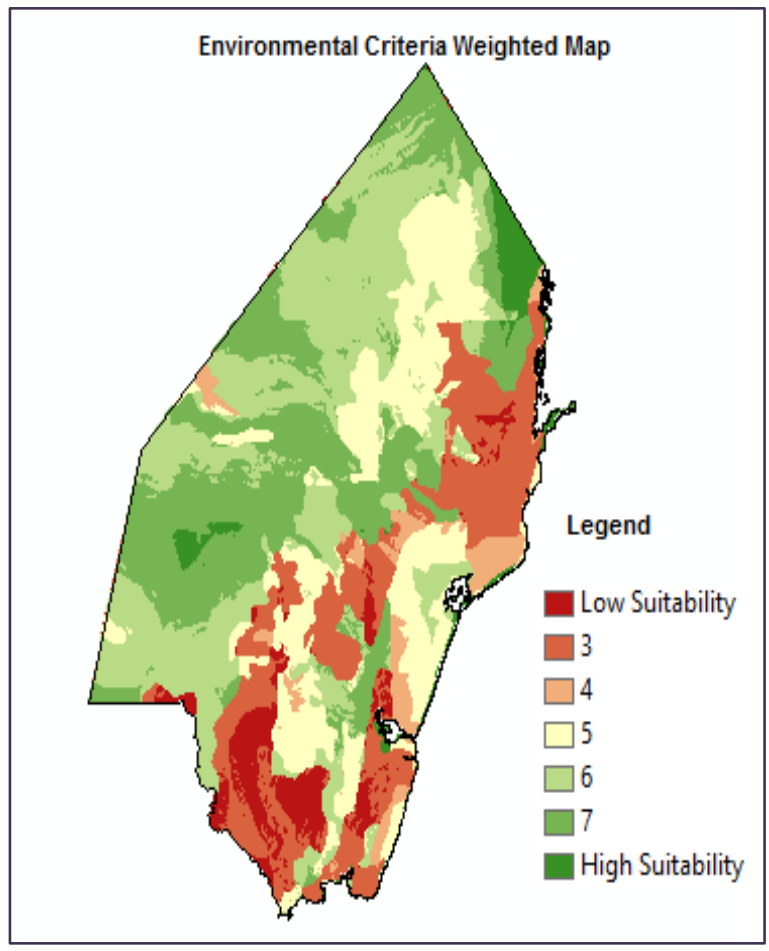

Figure 4:17 Environmental Criteria

Suitability Map

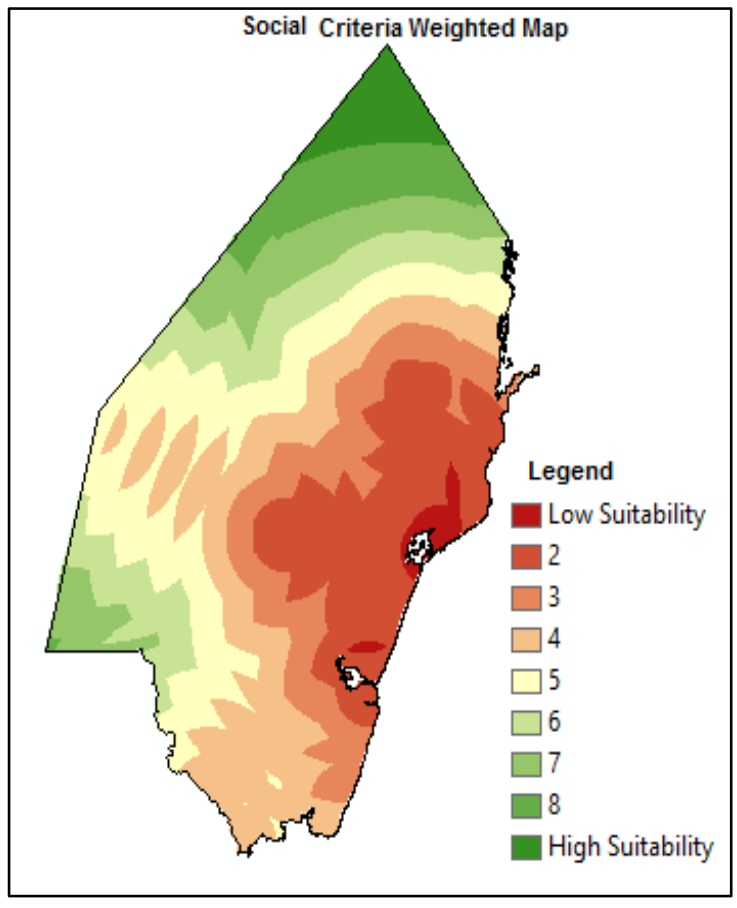

Figure 4:18 Social Criteria Suitability Map

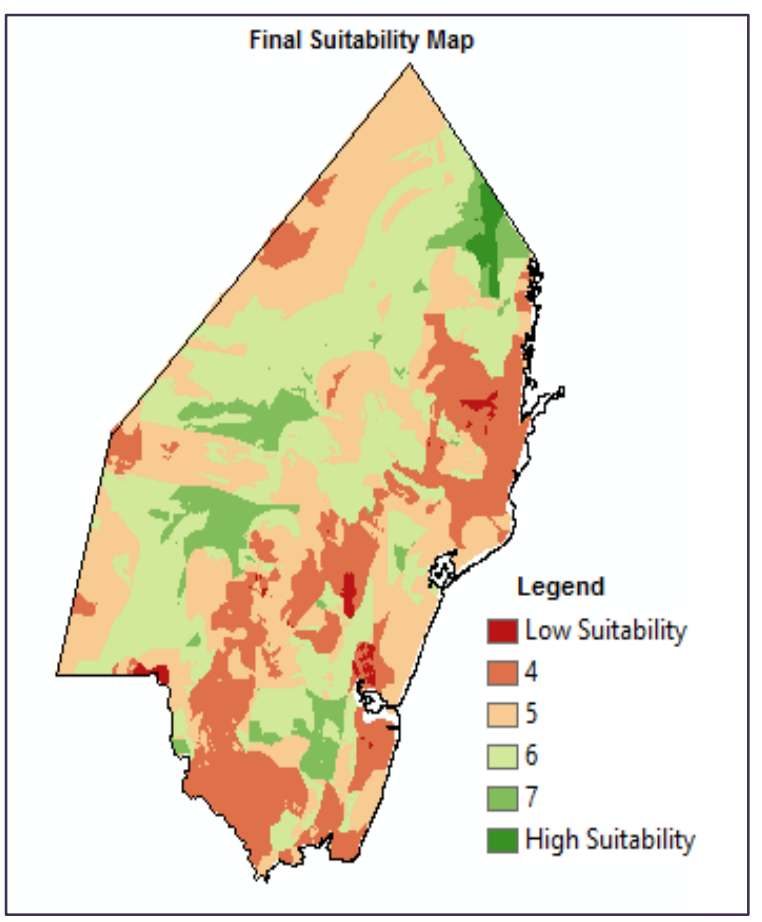

Figure 4:19 Combined Criteria Suitability Map 
It can be observed that eight prime locations have been identified as potential sites. This is illustrated below:

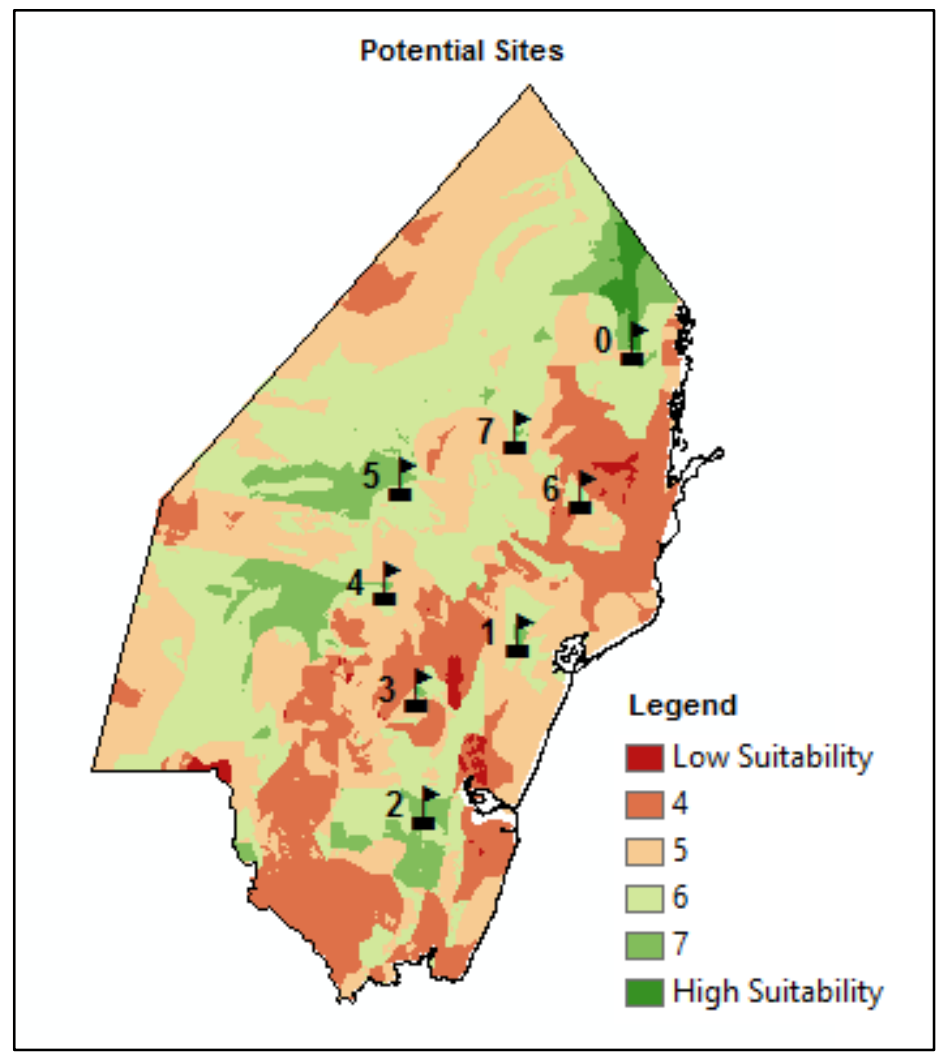

Figure 4:20 Potential Sites

These eight areas were assessed further using MCDA tools to identify the most suitable area. The tools used were AHP, VIKOR, and PROMETHEE.

\subsection{Site Performance Data}

The next step of analysis was to use ArcGIS to compute how each site performed with respect to each criteria. The following performance indicators were determined:

- The number of towns, both rural and urban, within a $40 \mathrm{KM}$ radius of each site.

- The number of healthcare facilities (Hf) within a $40 \mathrm{KM}$ radius of each site.

- The site's distance to the nearest existing road network.

- The site's distance to the nearest transformer location of the electrical grid network.

- The site's distance to the nearest river bank. 
- The site's distance to the nearest protected area.

- The type of area the site is located on with respect to land use.

- The cost of traversing the terrain from the site to the nearest road network. This cost was the least cost path computed by an integral tool within ArcGIS. The tool determines what path will incur the least cost with respect to the slope of the area from a starting point to an end point.

The first table below lists these criteria and their summarized descriptions and optimization objective. The second table list the performance of each site.

Table 4.15 Criteria Description and Objective

\begin{tabular}{lll}
\hline Criteria & Description & Objective \\
\hline Health Facility & Number within 40km Radius of Site & Maximize \\
Towns & Number within 40km Radius of Site & Maximize \\
Roads & Distance of site to nearest road (KM) & Minimize \\
River & Distance of site to nearest river (KM) & Maximize \\
Protected Area & Distance of site to nearest area (KM) & Maximize \\
Grid & Distance of site to nearest Transformer (KM) & Minimize \\
Land Use & Categorized land use (grade) & Maximize \\
Terrain & Cost of traversing Terrain from road to site & Minimize \\
\hline
\end{tabular}

Table 4.16 Site Performance Data Per Criteria

\begin{tabular}{c|rrrrrrrr}
\hline Criteria & $\begin{array}{c}\text { Health } \\
\text { Facility }\end{array}$ & Towns & Roads & Grid & River & $\begin{array}{c}\text { Protected } \\
\text { Area }\end{array}$ & Landuse & Terrain \\
\hline Objective & \multicolumn{1}{c}{ Max } & Max & Min & Min & Max & Max & Max & Min \\
\hline Site 0 & 11 & 4 & 6.8 & 7.1 & 10.7 & 49 & 8 & 0.027653 \\
Site 1 & 29 & 22 & 7.6 & 6.6 & 14.9 & 0 & 3 & 0.062755 \\
Site 2 & 34 & 15 & 7.1 & 1.6 & 0.9 & 19 & 8 & 0.217122 \\
Site 3 & 23 & 14 & 6.4 & 1.5 & 2.5 & 14.3 & 2 & 0.114707 \\
Site 4 & 16 & 2 & 6.3 & 9.3 & 10.3 & 22.8 & 8 & 0.042568 \\
Site 5 & 13 & 3 & 7.3 & 16.6 & 1.1 & 31.1 & 9 & 0.065253 \\
Site 6 & 28 & 14 & 3.7 & 3.9 & 1.7 & 17 & 8 & 0.031853 \\
Site 7 & 22 & 8 & 8.4 & 9.2 & 3.3 & 28.5 & 8 & 0.109786 \\
\hline
\end{tabular}




\section{MCDA ANALYSIS}

In this chapter, the eight sites identified from the spatial analysis were further assessed using AHP, VIKOR and PROMETHEE. The results were then compared and the best site selected.

\subsection{AHP}

In the previous chapter the calculations for assigning weights to the main criteria and subcriteria were elaborated. They were as shown below.

\subsubsection{Main Criteria Weights}

Table 5.1 First Hierarchy Weights

\begin{tabular}{l|c}
\hline Criteria & Weights \\
\hline Economic & 0.454545 \\
Environmental & 0.454545 \\
Social & 0.090909 \\
\hline
\end{tabular}

\subsubsection{Sub-Criteria Weights}

Table 5.2 Economic

Criteria Weights

\begin{tabular}{l|l}
\hline Criteria & Weight \\
\hline Roads & 0.454545 \\
Grid & 0.090909 \\
Health Fac. & 0.454545 \\
\hline
\end{tabular}

Table 5.3 Environmental

Criteria Weights

\begin{tabular}{l|c}
\hline Criteria & Weights \\
\hline Terrain & 0.2 \\
Landuse & 0.6 \\
Rivers & 0.2 \\
\hline
\end{tabular}

Table 5.4 Social Criteria Weights

\begin{tabular}{l|c}
\hline Criteria & Weights \\
\hline Towns & 0.5 \\
ProtAreas & 0.5 \\
& \\
\hline
\end{tabular}

\subsubsection{Site Weights}

The next task was to determine weights for each of the possible eight candidate sites with respect to each sub-criteria. The structure of the hierarchy is shown in the following page. 


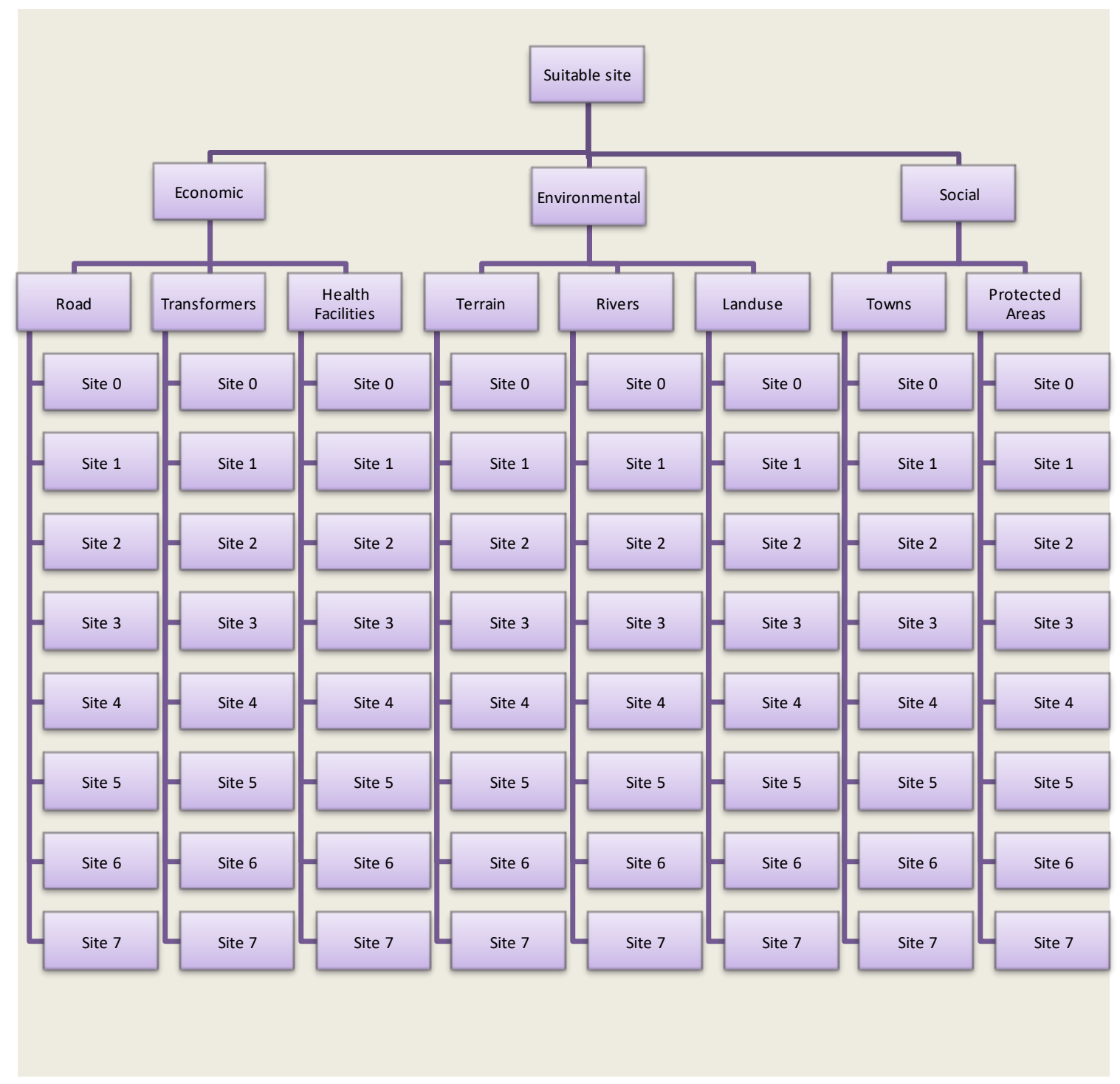

Figure 5:1 The Criteria and Site Alternative Hierarchy

In this study, the weights of the candidate sites were determined by calculating a site's relative performance with respect to the other sites per criteria. This involved normalizing its rating by calculating the ratio of its performance to the sum of all sites' performances. This was done for all criteria. The reason for employing this approach rather than the AHP approach of doing a pair-wise comparison based on the 9-scale grade was: to get precise relative weights that are reflective of each site's performance and to prevent the risk of introducing inconsistencies when arbitrarily assigning the 9 -scale grade values. 
Given the set of possible candidate sites $A=\left\{a_{i} \mid i=1,2, \ldots, m\right\}$ and a set of criteria $g=\left\{g_{j} \mid j=1,2, \ldots, n\right\}$, then let $g_{j}\left(a_{i}\right)$ represents the performance of site $s_{i}$ with respect to the $j$ th criterion.

The process was straightforward for criteria that had an objective of maximizing the performance value. It involved the following steps:

1) Determine the sum of all sites' performances for a given criteria. Let $P\left(g_{j}\right)$ represent this value for the $j$ th criteria.

$$
P\left(g_{j}\right)=\sum_{i=0}^{m} g_{j}\left(a_{i}\right)
$$

2) Compute the weight for each site for the $j$ th criteria by calculating the ratio shown below. Let $w_{j}\left(s_{i}\right)$ represent the weight of site $a_{i}$ with respect to criteria $j$.

$$
w_{j}\left(a_{i}\right)=\frac{g_{j}\left(a_{i}\right)}{P\left(g_{j}\right)}
$$

The table below shows the weights of the sites whose criteria needed to be maximized.

Table 5.5 Site Weights per Criteria (Maximization)

\begin{tabular}{l|llllllll}
\hline Criteria (j) & Site 0 & Site 1 & Site 2 & Site 3 & Site 4 & Site 5 & Site 6 & Site 7 \\
\hline Health Facilities & 0.0625 & 0.1647 & 0.1931 & 0.1306 & 0.0909 & 0.0738 & 0.1590 & 0.1250 \\
Towns & 0.0487 & 0.2682 & 0.1829 & 0.1707 & 0.0243 & 0.0365 & 0.1707 & 0.0975 \\
River & 0.2356 & 0.3281 & 0.0198 & 0.0550 & 0.2268 & 0.0242 & 0.0374 & 0.0726 \\
Protected Area & 0.2696 & 0.0000 & 0.1045 & 0.0787 & 0.1254 & 0.1711 & 0.0935 & 0.1568 \\
Landuse & 0.1481 & 0.0555 & 0.1481 & 0.0370 & 0.1481 & 0.1666 & 0.1481 & 0.1481 \\
\hline
\end{tabular}

For criteria that had an objective of minimizing the performance value, an additional initial step of inverting the performance values was performed. This was necessary to ensure the sites with low performance values were weighted higher than those with high performance values. The procedure is elaborated below:

1) Find the reciprocal of $g_{j}\left(a_{i}\right)$ for all sites for a given criteria. Let this be represented by

$$
\left(g_{j}\left(a_{i}\right)\right)^{\prime}
$$




$$
\left(g_{j}\left(a_{i}\right)\right)^{\prime}=\frac{1}{g_{j}\left(a_{i}\right)}
$$

2) Find the sum of all sites' reciprocated values for a given criteria. Let $P\left(g_{j}\right)$ represent this value for the $j$ th criteria.

$$
P\left(g_{j}\right)=\sum_{i=0}^{m}\left(g_{j}\left(a_{i}\right)\right)^{\prime}
$$

3) Compute the weight for each site for the $j$ th criteria by calculating the ratio shown below. Let $w_{j}\left(a_{i}\right)$ represent the weight of site $a_{i}$ with respect to criteria $j$.

$$
w_{j}\left(a_{i}\right)=\frac{\left(g_{j}\left(a_{i}\right)\right)^{\prime}}{P\left(g_{j}\right)}
$$

The table below shows the weights of the sites whose criteria needed to be maximized.

Table 5.6 Site Weights per Criteria (Minimization)

\begin{tabular}{l|llllllll}
\hline Criteria (j) & Site 0 & Site 1 & Site 2 & Site 3 & Site 4 & Site 5 & Site 6 & Site 7 \\
\hline Road & 0.1166 & 0.1043 & 0.1117 & 0.1239 & 0.1259 & 0.1086 & 0.2143 & 0.0944 \\
Transformers & 0.0665 & 0.0715 & 0.2952 & 0.3149 & 0.0507 & 0.0284 & 0.1211 & 0.0513 \\
Terrain & 0.2498 & 0.1100 & 0.0318 & 0.0602 & 0.1623 & 0.1058 & 0.2169 & 0.0629 \\
\hline
\end{tabular}

\subsubsection{Composite Weights}

The final step was to aggregate all the weights to compute the composite weight for each site.

Let:

a) $c w\left(a_{i}\right)$ represent the composite weight of site $i$.

b) The set of main criteria be represented as $F=\left\{f_{y} \mid y=1,2, \ldots, z\right\}$. Then $w f_{y}$ represents the weight of the $y$ th criteria in the first hierarchy.

c) The set of sub-criteria be represented as $G=\left\{g_{j} \mid j=1,2, \ldots, n\right\}$. Then $w g_{j}$ represent the weight of the $j$ th sub-criteria. 
For each site, the following formula was applied:

$$
c w\left(a_{i}\right)=\sum_{y=1}^{y=z} w f_{y}\left(\sum_{j=1}^{j=n}\left(w g_{j} * w_{j} a_{i}\right)\right)
$$

The calculated composite weights are shown in the table below:

Table 5.7 AHP Composite Weights and Ranking for Sites

\begin{tabular}{l|cccccccc}
\hline Composite Weights & Site 0 & Site 1 & Site 2 & Site 3 & Site 4 & Site 5 & Site 6 & Site 7 \\
\hline Economic & 0.0397 & 0.0585 & 0.0751 & 0.0656 & 0.0468 & 0.0388 & 0.0821 & 0.0474 \\
Environmental & 0.0845 & 0.0549 & 0.0450 & 0.0205 & 0.0757 & 0.0572 & 0.0635 & 0.0527 \\
Social & 0.0144 & 0.0121 & 0.0130 & 0.0113 & 0.0068 & 0.0094 & 0.0120 & 0.0115 \\
\hline Total Weight & $\mathbf{0 . 1 3 8 7}$ & $\mathbf{0 . 1 2 5 7}$ & $\mathbf{0 . 1 3 3 3}$ & $\mathbf{0 . 0 9 7 4}$ & $\mathbf{0 . 1 2 9 4}$ & $\mathbf{0 . 1 0 5 6}$ & $\mathbf{0 . 1 5 7 7}$ & $\mathbf{0 . 1 1 1 7}$ \\
Rank & $\mathbf{2}$ & $\mathbf{5}$ & $\mathbf{3}$ & $\mathbf{8}$ & $\mathbf{4}$ & $\mathbf{7}$ & $\mathbf{1}$ & $\mathbf{6}$ \\
\hline
\end{tabular}

Therefore based on the AHP calculations Site 6 is the best alternative. This site scored highest with respect to its economic criteria performance. This is a logical selection as the site is near a major urban centre, Malindi town. The site has the closest distance to the existing road network and electrical grid network. Furthermore, regardless of the fact that it didn't have the highest count of health facilities within a $40 \mathrm{KM}$ radius, it can still service several health facilities that are within a reasonable distance. The second and third best sites are Site 0 and Site 2 respectively. Site 2, just like Site 6, scored fairly high with respect to economic criteria. Again it is also near a major town, Kilifi. Site 0 performed best with respect to the environmental factors.

\subsection{VIKOR}

Given the set of possible candidate sites $A=\left\{a_{i} \mid i=1,2, \ldots, m\right\}$ and a set of criteria $g=\left\{g_{j} \mid j=1,2, \ldots, n\right\}$, then let $f_{i j}$ represents the performance of site $a_{i}$ with respect to the jth criterion

Step 1: The best value $f_{j}^{*}$ and worst value $f_{j}^{-}$for each criteria were determined.

- For a criterion that was to be maximised the $f_{j}^{*}$ was the value of the site that had the highest value. For $f_{j}^{-}$, the value is of the site that had the lowest value. 
- For a criterion that was to be minimised the $f_{j}^{*}$ was the value of the site that had the lowest value. For $f_{j}^{-}$, the value is of the site that had the highest value.

The values determined are shown in the following table:

Table 5.8 Best and Worst Values per Criteria

\begin{tabular}{c|rrrrrrrr}
\hline Criteria & \multicolumn{1}{|c}{$\begin{array}{c}\text { Health } \\
\text { Facilities }\end{array}$} & Towns & Roads & River & $\begin{array}{c}\text { Protected } \\
\text { Area }\end{array}$ & Grid & Landuse & Terrain \\
\hline Objective & Max & Max & Min & Max & Max & Min & Max & Min \\
$\boldsymbol{f}_{\boldsymbol{j}}^{*}$ & 34 & 22 & 3.7 & 14.9 & 49 & 1.5 & 9 & 0.02765 \\
$\boldsymbol{f}_{\boldsymbol{j}}^{-}$ & 11 & 2 & 8.4 & 0.9 & 0 & 16.6 & 2 & 0.21712 \\
\hline
\end{tabular}

Step 2: The utility measure $S_{i}$ and the regret measure $R_{i}$ were then computed. The results are shown in the following tables:

The utility values were computed using the formula shown below:

$$
S_{i}=\sum_{j=1}^{n} w_{j}\left(f_{j}^{*}-f_{i j}\right) /\left(f_{j}^{*}-f_{j}^{-}\right)
$$

Table 5.9 Utility Measure Values

\begin{tabular}{c|cccccccccc}
\hline & Site 0 & Site 1 & Site 2 & Site 3 & Site 4 & Site 5 & Site 6 & Site 7 & $\boldsymbol{S}^{*}$ (min) & $\boldsymbol{S}^{*}$ (max) \\
\hline $\boldsymbol{S}_{\boldsymbol{i}}$ & 0.465 & 0.526 & 0.414 & 0.662 & 0.443 & 0.555 & 0.235 & 0.540 & 0.235 & 0.662 \\
\hline
\end{tabular}

The regret measure was computed as shown below:

$$
R_{i}=\max _{j} w_{j}\left(f_{j}^{*}-f_{i j}\right) /\left(f_{j}^{*}-f_{j}^{-}\right)
$$

Table 5.10 Regret Measure Values

\begin{tabular}{c|cccccccccc}
\hline & Site 0 & Site 1 & Site 2 & Site 3 & Site 4 & Site 5 & Site 6 & Site 7 & $\boldsymbol{R}^{*}$ (min) & $\boldsymbol{R}^{*}$ (max) \\
\hline $\boldsymbol{R}_{\boldsymbol{i}}$ & 0.206 & 0.233 & 0.149 & 0.272 & 0.161 & 0.188 & 0.085 & 0.206 & 0.085 & 0.272 \\
\hline
\end{tabular}


Step 3: Next the values $Q_{i}$ were computed by the relation

$$
Q_{i}=\frac{v\left(S_{i}-S^{*}\right)}{S^{-}-S^{*}}+\frac{(1-v)\left(R_{i}-R^{*}\right)}{R^{-}-R^{*}}
$$

Where $v$ was selected to be 0.5 .

Table 5.11 Qi Values

\begin{tabular}{l|llllllll}
\hline & Site 0 & Site 1 & Site 2 & Site 3 & Site 4 & Site 5 & Site 6 & Site 6 \\
\hline $\boldsymbol{Q}_{\boldsymbol{i}}$ & 0.592 & 0.736 & 0.379 & 1.000 & 0.446 & 0.649 & 0.000 & 0.679 \\
\hline
\end{tabular}

Step 4: The above $Q_{i}, S_{i}$ and $R_{i}$ were sorted in increasing order. The sites were then ranked according to this sorting. The three ranking lists are shown below.

Table $5.12 Q_{i}$ Ranking

\begin{tabular}{c|cccccccc}
\hline & Site 0 & Site 1 & Site 2 & Site 3 & Site 4 & Site 5 & Site 6 & Site 7 \\
\hline $\boldsymbol{Q}_{\boldsymbol{i}}$ & 0.592 & 0.736 & 0.379 & 1.000 & 0.446 & 0.649 & 0.000 & 0.679 \\
Ranks & 4 & 7 & 2 & 8 & 3 & 5 & 1 & 6 \\
\hline
\end{tabular}

Table $5.13 S_{i}$ Ranking

\begin{tabular}{c|cccccccc}
\hline & Site 0 & Site 1 & Site 2 & Site 3 & Site 4 & Site 5 & Site 6 & Site 7 \\
\hline $\boldsymbol{S}_{\boldsymbol{i}}$ & 0.465 & 0.526 & 0.414 & 0.662 & 0.443 & 0.555 & 0.235 & 0.540 \\
Ranks & 4 & 5 & 2 & 8 & 3 & 7 & 1 & 6 \\
\hline
\end{tabular}

Table $5.14 R_{i}$ Ranking

\begin{tabular}{c|cccccccc}
\hline & Site 0 & Site 1 & Site 2 & Site 3 & Site 4 & Site 5 & Site 6 & Site 7 \\
\hline $\boldsymbol{R}_{\boldsymbol{i}}$ & 0.206 & 0.233 & 0.149 & 0.272 & 0.161 & 0.188 & 0.085 & 0.206 \\
Ranks & 5 & 7 & 2 & 8 & 3 & 4 & 1 & 4 \\
\hline
\end{tabular}

Step 5: Based on the above rankings, the site with the lowest $Q_{i}$ value was Site 6. It also has the lowest $S_{i}$ and $R_{i}$ values. This alternative was considered the best, as it met the following conditions: 
- It had an acceptable advantage:

The difference between its $Q$ value and that of Site 2 which was ranked second best was higher than $1 /(m-1)$ where $m$ is the number of alternatives. This is illustrated below:

$$
\begin{aligned}
& 0.379888-0 \geq \frac{1}{8-1} \\
& 0.379888 \geq 0.142857
\end{aligned}
$$

- Site 6 was also ranked best by both $S$ and $R$ values as illustrated in the tables above.

\subsection{PROMETHEE II}

Step 1: The following information was determined

- Weights of the criteria;

The composite AHP weights were used. These are shown below:

Table 5.15 AHP Composite Weights

\begin{tabular}{c|cccccccc}
\hline Sub-Criteria & Road & Grid & $\begin{array}{l}\text { Health } \\
\text { Facility }\end{array}$ & Terrain & Landuse & Rivers & Towns & $\begin{array}{c}\text { Protected } \\
\text { Areas }\end{array}$ \\
\hline Composite Weights & 0.2062 & 0.0413 & 0.2066 & 0.0909 & 0.2727 & 0.0909 & 0.0454 & 0.0454 \\
\hline
\end{tabular}

- The type III preference function was selected for all criteria. The respective $p$ values, the strict preference threshold, are listed below:

Table 5.16 Criteria P-Values

\begin{tabular}{l|cccccccc}
\hline Criteria & $\begin{array}{c}\text { Health } \\
\text { Facility }\end{array}$ & Towns & Roads & River & $\begin{array}{c}\text { Protected } \\
\text { Area }\end{array}$ & Grid & Landuse & Terrain \\
\hline p-value & 9 & 15 & 3.5 & 10 & 30 & 10 & 5 & 0.15 \\
\hline
\end{tabular}


Step 2: A pair-wise comparison between all pairs of alternative sites $a$ and $b$ was performed to calculate the difference $d_{j}$. Let the notation $g_{j}(a)$ represent the performance of site $a$ with respect to criterion $j$. The difference is then calculated as shown below:

$$
d_{j}=g_{j}(a)-g_{j}(b)
$$

Step 3: The type III preference function $P_{j}(a, b)$ determined in step 1 was applied for all pairs of actions. The function is shown below:

$$
H(D)= \begin{cases}\frac{\left|d_{j}\right|}{p}, & \left|d_{j}\right| \leq p \\ 1 & \left|d_{j}\right|>p\end{cases}
$$

Step 4: The preference index $\pi(a, b)$ of every alternative $a$ over alternative $b$ was calculated. This index indicates the preference of alternative $a$ over $b$, all criteria being considered. It is calculated as shown below and the results are as follows:

$$
\pi(a, b)=\sum_{\mathrm{j}=1}^{\mathrm{n}} \mathrm{W}_{\mathrm{j}} \mathrm{P}_{\mathrm{j}}(\mathrm{a}, \mathrm{b}) \quad \sum_{j=1}^{n} W_{j}=1
$$

Table 5.17 Preference Index Values

\begin{tabular}{l|llllllll}
\hline & Site 0 & Site 1 & Site 2 & Site 3 & Site 4 & Site 5 & Site 6 & Site 7 \\
\hline Site 0 & & 0.3866 & 0.2431 & 0.4454 & 0.0675 & 0.2089 & 0.1298 & 0.2512 \\
Site 1 & 0.2923 & & 0.2030 & 0.3389 & 0.3050 & 0.3858 & 0.1381 & 0.3805 \\
Site 2 & 0.2626 & 0.4664 & & 0.4894 & 0.2778 & 0.2961 & 0.1533 & 0.3359 \\
Site 3 & 0.2836 & 0.1135 & 0.1183 & & 0.2292 & 0.3471 & 0.0171 & 0.1910 \\
Site 4 & 0.1443 & 0.3962 & 0.2293 & 0.4061 & & 0.2554 & 0.0869 & 0.2283 \\
Site 5 & 0.1004 & 0.3358 & 0.1656 & 0.3281 & 0.0701 & & 0.0759 & 0.1504 \\
Site 6 & 0.4331 & 0.5349 & 0.2988 & 0.6012 & 0.4252 & 0.5135 & & 0.4316 \\
Site 7 & 0.2187 & 0.3159 & 0.1012 & 0.3044 & 0.1649 & 0.2723 & 0.0319 & \\
\hline
\end{tabular}

Step 5: For outranking evaluations, the following values were calculated:

1) The leaving flow, which is the outranking power of alternative $a$.

$$
\emptyset^{+}(a)=\frac{1}{n-1} \sum_{b \in A} \pi(a, b), \quad b \neq a
$$


For any given site, this was the summation of the values along its respective row in the preference index table. The values obtained are shown below:

Table 5.18 Leaving Flow Values

\begin{tabular}{c|cccccccc}
\hline & Site 0 & Site 1 & Site 2 & Site 3 & Site 4 & Site 5 & Site 6 & Site 7 \\
\hline$\phi+(\mathbf{S})$ & 1.732 & 2.043 & 2.281 & 1.300 & 1.746 & 1.226 & 3.238 & 1.409 \\
\hline
\end{tabular}

2) The entering flow, the outranked power of alternative $a$.

$$
\emptyset^{-}(a)=\frac{1}{n-1} \sum_{b \in A} \pi(b, a), \quad b \neq a
$$

For any given site, this was the summation of the values along its respective column in the preference index table. The values obtained are shown below:

Table 5.19 Entering Flow Values

\begin{tabular}{c|cccccccc}
\hline & Site 0 & Site 1 & Site 2 & Site 3 & Site 4 & Site 5 & Site 6 & Site 7 \\
\hline$\phi-(\mathbf{S})$ & 1.735 & 2.549 & 1.359 & 2.913 & 1.540 & 2.279 & 0.633 & 1.969 \\
\hline
\end{tabular}

3) The net flow

$$
\emptyset(a)=\emptyset^{+}(a)-\emptyset^{-}(a)
$$

Table 5.20 Net Flow Values

\begin{tabular}{l|cccccccc}
\hline & Site 0 & Site 1 & Site 2 & Site 3 & Site 4 & Site 5 & Site 6 & Site 7 \\
\hline Net Flow & -0.00238 & -0.50603 & 0.92219 & -1.61367 & 0.206726 & -1.05281 & 2.60545 & -0.55947 \\
Ranks & 4 & 5 & 2 & 8 & 3 & 7 & 1 & 6 \\
\hline
\end{tabular}

The net flow was used to induce a complete pre-order. From the ranking shown in the table above, site 6 is the best alternative. This was followed by site 2 , then site 4 . 


\subsection{DISCUSSION}

Table 5.21 Ranking Comparison

\begin{tabular}{c|ccc}
\hline Rank & AHP & VIKOR & PROMETHEE II \\
\hline $\mathbf{1}$ & Site 6 & Site 6 & Site 6 \\
$\mathbf{2}$ & Site 0 & Site 2 & Site 2 \\
$\mathbf{3}$ & Site 2 & Site 4 & Site 4 \\
$\mathbf{4}$ & Site 4 & Site 0 & Site 0 \\
$\mathbf{5}$ & Site 1 & Site 5 & Site 1 \\
$\mathbf{6}$ & Site 7 & Site 7 & Site 7 \\
$\mathbf{7}$ & Site 5 & Site 1 & Site 5 \\
$\mathbf{8}$ & Site 3 & Site 3 & Site 3 \\
\hline
\end{tabular}

The results across all three methods were reasonably consistent.

- The best identified solution by all three methods was site 6 . This site is nearest to the major urban centre, Malindi town. The site scored highest with respect to its economic criteria performance. The site has the closest distance to the existing road network and electrical grid network. Furthermore, regardless of the fact that it doesn't have the highest count of health facilities within a $40 \mathrm{KM}$ radius, it has the second highest count and can thus service several health facilities that are within a reasonable distance. Environmentally, in terms of landuse it is located in a woodland area, a category that was ranked second highest. It performs relatively poorly with regards to distance to the rivers as it is only $1.7 \mathrm{Km}$ away. But this is assumed to be an appropriate buffer distance .

- It was further observed that site 2, was also a reasonable option as it was ranked second by both PROMETHEE II and VIKOR. This site is closest to another major urban centre, Kilifi town. It scored highly with regards to economic criteria. It has the highest count of health facilities within target radius and is close to the existing road and grid network.

- The poorest performing sites were Sites 1, 3, 5 and 7. Site 3 was the worst consistently across all three methods. The sites 1 and 3 generally performed poorly with regards to environmental criteria. Site 3 is located in an area that is used for agricultural purposes. Site 1 on the other hand is within a protected forest. Sites 5 and 7 performed well with regards to environmental criteria, but performed poorly on the economic front. Site 5 and 7 only have three and eight health facilities within a 40KM radius. This largely due to the fact they are farthest from the urban areas. 
This page has been left blank intentionally. 


\section{CONCLUSION}

This thesis set out to offer an approach of handling healthcare waste in Kilifi county which is faced with an array of problems. These problems include healthcare facilities that have limited funds to invest in disposal facilities or tools that are compliant with both local and international laws, healthcare facilities that have poorly sited incinerators and regulatory bodies that are overwhelmed with the task of ensuring all healthcare facilities in the county have compliant means of disposal.

The solution suggested in this study involves setting up a modernized compliant centralized incinerator. This would help resolve the funding issue by allowing several health facilities to pool their funds to realize such a vision. The health facilities would thus be afforded with an avenue through which to properly handle their waste. The approach would also alleviate the challenge faced by regulatory bodies of having to monitor several facilities. Through such an approach, monitoring and control could be easily administered from a single point .

The challenge then left would be to site such a centralized facility in a suitable area. From the perspective of siting an undesirable facility such as an incinerator, it is important to consider not only economic factors, but also increasingly nowadays, environmental and social factor. Economic issues, in terms of initial investment costs have largely been the primary concern for investment stakeholders in Kenya. This cannot be left unchallenged, especially so, with regards to facilities that can pose a health hazard. Furthermore, coastal towns in Kenya mainly depend on revenues from touristic activities. Having an incinerator within a town can consequently result in a backlash from the residents.

The methodology presented in this study offers a comprehensive approach for the systematic evaluation of both qualitative and quantitative decision factors. The approach entails first conducting a spatial analysis of the target area. The spatial analysis was carried out under three visions: the economic, environmental and social visions. This resulted in three different suitability layer maps. These layers were then weighted and overlaid. From this the final candidate sites, eight of them, were identified.

These sites were then assessed using the MCDA tools AHP, VIKOR and PROMETHEE II. The sites were analysed based on how they performed with regard to identified criteria. The results were very conclusive in that all three methods identified site 6 as the best alternative. Furthermore, all methods generally identified the same best performing and worst performing sites. Therefore, since the results were consistent, it can be concluded that in the face of 
conflicting criteria, the methodology used in this study was robust and the resulting findings of the study valid.

There are several areas for improvement in this study. A more complete dataset could be used to perform the spatial analysis. The dataset used in this study was downloaded from open source websites. But it was observed that some were incomplete. For instance Kilifi county has over 350 health facilities, but the dataset used, only included around 150 facilities. Through necessary funding, field research to can be carried out prior to performing the spatial analysis, so a more complete dataset is used. This will give clearer picture of the actual state on the ground. Another criteria that is also relevant with regards to incineration siting studies is the pollution dispersion impact index. This index quantifies the impact of airborne pollutants emitted by the incinerator that attain different concentrations at the ground level, after dispersion in the atmosphere. The impact is dependent on several climatic conditions as well as content and stability of substances in the emissions.

In conclusion, this thesis suggests an approach in resolving the challenges faced by health facilities lacking proper means of waste disposal and overwhelmed regulatory bodies in the task of monitoring and control. The study suggests setting up a centralized incinerator to face the above challenges. The methodology used to site the incinerator integrates GIS and MCDA tools, providing a simple way of efficiently identifying an appropriate location. 


\section{BIBLIOGRAPHY}

Achillas, C., Moussiopoulos, N., Karagiannidis, A., Banias, G., \& G.Perkoulidis. (2013). The use of multi-criteria decision analysis to tackle waste management problems: A literature review. Waste Management \& Research, 31(2), 115-129.

Allsopp, M., Costner, P., \& Johnston, P. (2011). Incineration and Human Health. Exeter: Greenpeace Research Laboratories.

Alzamili, H., El-Mewafi, M., Besh, A., \& Awad, A. (2015). GIS Based Multi Criteria Decision Analysis for Ind ustrial Site Selection in Al-Nasiriyah City in Iraq. International Journal of Scientific \& Engineering Research, , Volume 6, Issue 7.

Arıkan, E., Şimşit-Kalender, Z. T., \& Vayvay, Ö. (2017). Solid waste disposal methodology selection using multi-criteria decision making methods and an application in Turkey. Journal of Cleaner Production, 142, 403-412.

Bickel, S. (2007). Healthcare waste: Generation, handling, treatment and disposal. In Environmental Guidelines for Small-Scale Activities in Africa. SD Publishing Series.

Bosompem, C., Stemn, E., \& Fei-Baffoe, B. (2016). Multi-criteria GIS-based siting of transfer station for Municipal Solid Waste: The case of Kumasi Metropolitan Area, Ghana. Waste Management \& Research, 34(10) 1054-1063.

Cheng, S., Chan, C., \& Huang, G. (2003). An integrated multi-criteria decision analysis and inexact mixed integer linear programming approach for solid waste management. Engineering Applications of Artificial Intelligence, 16(5-6), 543-554.

Christos, C., \& Katia, L. (2011). Benefits from GIS Based Modelling for Municipal Solid Waste. In S. Kumar (Ed.), Integrated Waste Management-Volume I(pp. 417-437). InTech.

Development \& Training Services. (2012). Environmental Compliance: Health Care Waste Management in Kenya. Virginia: USAID.

Eskandari, M., Homaee, M., Mahmoodi, S., Pazira, E., \& Genuchten, M. V. (2015). Optimizing Landfill Site Selection by Using Land Classification Maps. Environmental Science And Pollution Research, 22(10), 7754-7765. 
Ferreti, V. (2011). A Multicriteria Spatial Decision Support System Development for Siting a Landfill in the Province of Torino (Italy). Journal of Multi-Criteria Decision Analysis, $18(5-6), 231-252$.

Figueira, J., Mousseau, V., \& Roy, B. (2005). ELECTRE METHODS. In J. Figueira, S. Greco, \& M. Ehrgott (Eds.), Multiple Criteria Decision Analysis: State of the Art Surveys (pp. 133-162). Verlag, Boston, Dordrecht, London: Springer .

Hyde, K. (2006). Uncertainty Analysis Methods for Multi-Criteria Decision Analysis. Australia: University of Adelaide.

Issa, S., \& Shehhi, B. (2012). A GIS-Based Multi-Criteria Evaluation System for Selection of Landfill Sites: A case study from Abu Dhabi, United Arab Emirates. International Archives of the Photogrammetry, Remote Sensing and Spatial Information Sciences, 39(B2), 133-138.

Kazan, H., \& Çiftci, C. (2013). Transport Path Selection: Multi-Criteria Comparison. International Journal of Operations and Logistics Management, Volume: 2, Issue: 4, Pages: 33-48.

Kilifi County. (2013). First Kilifi County Integrated Development Plan 2013-2017. Kilifi: Kilifi County.

Kontos, T., Komilis, D., \& Halvadakis, C. (2005). Siting MSW landfills with a spatial. Waste Management, 25, 818-832.

Koros, K. (2014). AllAfrica.com. Retrieved September 20, 2015, from http://allafrica.com/stories/201411111021.html

Malczewski, J. (2004). GIS-based land-use suitability analysis: a critical overview. Progress In Planning, 62(1), 3-65.

Mazrui, N. (2010). Medical Waste Management in Kenya: Opportunities for Improvement. Tropical Resource Bulletin, 29, 66-70. Retrieved from https://environment.yale.edu/tri/uploads/Nashaat_Mazrui.pdf

Milosevic, I., \& Naunovic, Z. (2013). The application of a multi-parameter analysis in choosing the location of a new solid waste landfill in Serbia. Waste Mnagement and Research, 31(10), 1019-1027. 
Ministry Of Health. (2015). Health Care Waste Management Strategic Plan 2015-2020.

Nairobi: Government of Kenya.

National Aids and STI Control Programme. (2007). National Policy on Injection Safety and Medical Waste Management. Nairobi: Ministry of Health.

Önüt, S., \& Soner, S. (2008). Transshipment site selection using the AHP and TOPSIS approaches under fuzzy . Waste Management, 28, 1552-1559.

Opricovic, S., \& Tzeng, G.-H. (2004). Compromise solution by MCDM methods: A comparative analysis of VIKOR and TOPSIS . European Journal of Operational Research, 156(2), 445-455.

Pohekar, S., \& Ramachandran, M. (2004). Application of multi-criteria decision making to sustainable energy planning-A review. Renewable and Sustainable Energy Reviews, $8,365-381$.

Rikalovic, A., Cosic, I., \& Lazarevic, D. (2014). GIS Based Multi-criteria Analysis for Industrial Site Selection. Procedia Engineering, 69, 1054-1063.

Sener, S., Sener, E., Nas, B ., \& Karagüzel, R. (2010). Combining AHP with GIS for landfill site selection: A case study in the Lake Beysehir catchment area (Konya, Turkey). Waste Management, 30(11), 2037-2046.

Shofade, O. J. (2011). Considering hierarchical structure of criteria in ELECTRE decision aiding methods. Tarragona: Universitat Rovira i Virgili.

Sumathi, V., Natesan, U., \& Sarkar, C. (2008). GIS-based approach for optimized siting of municipal solid waste landfill. Waste Management, 28, 2146-2160.

Tang, S., Boyer, O., Pedram, A., Yusuff, R., \& Zulkifli, N. (2013). A Review on Multiple Criteria Undesirable Facility Location Problems. Journal Of Basic And Applied Scientific Research, 3(8), 708-713.

Tavares, G., Zsigraiova, Z., \& Semiao, V . (2011). Multi-criteria GIS-based siting of an incineration plant for municipal solid waste. Waste Management, 31 (9-10), 19601972. 
Tavares, G., Zsigraiová, Z., \& Semiao, V . (2011). Multi-criteria GIS-based siting of an incineration plant for municipal solid waste. Waste Management, 31, 1960-1972.

Triantaphyllou, E., Shu, B., Sanchez, S. N., \& Ray, T. (1998). Multi-Criteria Decision Making: An Operations Research Approach. In J. Webster(Ed.), Encyclopedia of Electrical and Electronics Engineering (pp. 175-186). New York: John Wiley \& Sons.

Tsiko, R. G. (2016). Tsiko, R. G. (2016). Site selection using GIS, Simulated Annealing, AHP and EVAMIX approaches under Fuzzy Set Theory: A case study of landfill siting in Blantyre City, Malawi. Journal of American Science, 12(10).

Tuzkaya, G., Önüt, S., Tuzkaya, U. R., \& Gülsün, B. (2008). An analytic network process approach for locating undesirable facilities: An example from Istanbul, Turkey. Journal of Environmental Management, 88, 970-983.

Tzeng, G., \& Huang, J. (2011). Multiple Attribute Decision Making Methods and Applications (1st ed.). Boca Raton: CRC Press.

Whaiduzzaman, M., Gani, A., Anuar, N. B., \& Shiraz, M. (2014). Cloud Service Selection Using Multicriteria Decision Analysis. The Scientific World Journal, Volume 2014(Article ID 459375).

WHO. (2004). Findings on an Assessment of Small-scale Incinerators for Health-care Waste. Geneva: WHO Publishers.

WHO. (2005). Management of Solid Health-Care Waste at Primary Health-Care Centres: A Decision-Making Guide. Geneva: WHO Publishers.

Zakaria, B., Abdullah, R., Ramli, M. F., \& Latif, P. A. (2013). GIS-Based Site Selection for Hazardous Waste Disposal Facilities in Penang and Kedah. In A. Aris, T. Tengku Ismail, R. Harun, A. Abdullah, \& M. Ishak (Eds.), From Sources to Solution (pp. 257260). Singapore: Springer, Singapore. 


\section{RESUME}

Husna Ali Hariz was born in 1987 in Nairobi, Kenya. She completed her primary and secondary school studies in Nairobi and Mombasa respectively. She started her undergraduate studies in 2007, pursuing a course in Computer Science at the University of Nairobi in Kenya. She completed this degree in 2011 with a First Class Honours. She worked at an audit firm for three month thereafter, at which point she was awarded a scholarship by Türkiye Burslan in 2012. She has since then been doing her Masters Degree in Industrial Engineering at Marmara University. 